\title{
Field Trial and Molecular Characterization of RNAi-Transgenic Tomato Plants That Exhibit Resistance to Tomato Yellow Leaf Curl Geminivirus
}

\author{
Alejandro Fuentes, ${ }^{1}$ Natacha Carlos, ${ }^{1}$ Yoslaine Ruiz, ${ }^{1}$ Danay Callard, ${ }^{1}$ Yadira Sánchez, ${ }^{1}$ \\ María Elena Ochagavía, ${ }^{1}$ Jonathan Seguin, ${ }^{2,3}$ Nachelli Malpica-López, ${ }^{2}$ Thomas Hohn, ${ }^{2}$ \\ Maria Rita Lecca, ${ }^{4}$ Rosabel Pérez, ${ }^{1}$ Vivian Doreste, ${ }^{1}$ Hubert Rehrauer, ${ }^{4}$ Laurent Farinelli, ${ }^{3}$ \\ Merardo Pujol, ${ }^{1}$ and Mikhail M. Pooggin ${ }^{2}$ \\ ${ }^{1}$ Center for Genetic Engineering and Biotechnology, calle 31 entre 158 y 190, Cubanacan Playa, Apdo 6162, Habana 10600, \\ Cuba; ${ }^{2}$ University of Basel, Department of Environmental Sciences, Botany, Hebelstrasse 1, 4056 Basel, Switzerland; \\ ${ }^{3}$ FASTERIS SA, Ch. Du Pont-du-Centenaire 109, 1228 Plan-les-Ouates, Switzerland; and ${ }^{4}$ Functional Genomics Center \\ ETH Zurich, University of Zurich, Winterthurerstrasse 190/Y32 H80, 8057 Zurich, Switzerland
}

Submitted 14 August 2015. Accepted 16 December 2015.

RNA interference (RNAi) is a widely used approach to generate virus-resistant transgenic crops. However, issues of agricultural importance like the long-term durability of RNAimediated resistance under field conditions and the potential side effects provoked in the plant by the stable RNAi expression remain poorly investigated. Here, we performed field trials and molecular characterization studies of two homozygous transgenic tomato lines, with different selection markers, expressing an intron-hairpin RNA cognate to the Tomato yellow leaf curl virus (TYLCV) $\mathrm{C} 1$ gene. The tested F6 and F4 progenies of the respective kanamycin- and basta-resistant plants exhibited unchanged field resistance to TYLCV and stably expressed the transgene-derived short interfering RNA (siRNAs) to represent 6 to $8 \%$ of the total plant small RNAs. This value outnumbered the average percentage of viral siRNAs in the nontransformed plants exposed to TYLCV-infested whiteflies. As a result of the RNAi transgene expression, a common set of up- and downregulated genes was revealed in the transcriptome profile of the plants selected from either of the two transgenic events. A previously unidentified geminivirus causing no symptoms of viral disease was detected in some of the transgenic plants. The novel virus acquired $V 1$ and $V 2$ genes from TYLCV and $C 1, C 2$, $C 3$, and $C 4$ genes from a distantly related geminivirus and, thereby, it could evade the repressive sequence-specific action of transgene-derived siRNAs. Our findings shed light on the mechanisms of siRNA-directed antiviral silencing in transgenic

Nucleotide sequence data is available in the GenBank database under accession numbers KM926623 for TLV-T1, KM926624 for TLV-T2, KM926625 for TYLCV-C1, and KM926626 for TYLCV-C2 and the microarray data were deposited to the Gene Expression Omnibus accession number GSE63708.

Corresponding authors: M. Pooggin; E-mail: Mikhail.Pooggin@unibas.ch; Telephone: +41 6126723 14; Fax: +41 6126723 30; and A. Fuentes; E-mail: alejandro.fuentes@cigb.edu.cu

*The $\boldsymbol{e}$-Xtra logo stands for "electronic extra" and indicates that four supplementary figures, one supplementary table, three datasets, and supplementary text are published online.

(C) 2016 The American Phytopathological Society plants and highlight the applicability limitations of this technology as it may alter the transcriptional pattern of nontarget genes.

Tomato yellow leaf curl virus (TYLCV) is a circular singlestranded DNA virus (Navot et al. 1991) from genus Begomovirus of the family Geminiviridae. The members of this family, collectively known as geminiviruses, replicate in the nucleus of infected cells by rolling circle and recombination-dependent mechanisms, using, in both cases, a circular double-stranded DNA (dsDNA) replicative intermediate that also serves as a template for the Pol II-driven bidirectional transcription of viral genes (Hanley-Bowdoin et al. 2013; Pooggin 2013). Being a typical monopartite begomovirus, TYLCV possesses six genes that are transcribed by Pol II from virion and complementary strands of the $2.8-\mathrm{kb}$ circular dsDNA, in the rightward and leftward directions. The leftward genes code for the Rep/C1 replication initiator (Desbiez et al. 1995), the TrAP/C2 putative transcriptional activator and silencing suppressor (Dong et al. 2003; Noris et al. 1996), the REn/C3 replication enhancer (Settlage et al. 2005), and the putative movement protein and silencing suppressor C4 (Jupin et al. 1994; Luna et al. 2012; Rojas et al. 2001; Xie et al. 2013), while the rightward genes code for the coat protein V1/CP (Hallan and Gafni 2001) and the putative movement protein and silencing suppressor V2 (Luna et al. 2012; Rojas et al. 2001; Wang et al. 2014; Zrachya et al. 2007).

TYLCV is a major causative agent of tomato yellow leaf curl disease. This disease is regarded as the most important biotic threat for tomato production around the world, owing to TYLCV's diversification and spread from the Middle East through many regions of the Old World and the New World, including Cuba (Lefeuvre et al. 2010; Moriones and NavasCastillo 2000). The infection of tomato fields with TYLCV and TYLCV-like begomoviruses, which are all transmitted by the whitefly Bemisia tabaci, can lead to the loss of entire harvests if inoculation takes place at an early point of the cultivation cycle (Gómez et al. 2004). Several different approaches have been followed during the last two decades in an attempt to overcome the spread of TYLCV, among which the use of resistant tomato plants stands as one of most effective and friendly solutions (Friedmann et al. 1998; Lapidot et al. 1997). Commercial tomato 
plants tolerant or resistant to TYLCV have been obtained by introgression of resistance genes from wild Solanum lycopersicum relatives and have been marketed for some time now. An examination of the molecular basis of their phenotypes has revealed that, in two genotypes (Ty-1 and Ty-3), TYLCV resistance is conferred by an RNA-directed RNA polymerase (RDR) gene implicated in RNA silencing (Butterbach et al. 2014; Verlaan et al. 2013). Unfortunately, the practice of introgression is often accompanied by changes in the agronomical properties of the recipient cultivars, the outcrossing of which is a time-consuming process. Hence, efforts have been underway to develop tomato and other crop plants resistant to geminiviruses using more expeditious approaches. One such approach is the use of RNA interference (RNAi), in which the RNA silencing-based antiviral defense mechanism of the crop is preprogrammed through the transgenic expression of a hairpin double-stranded RNA (dsRNA) cognate to a viral genome (Bonfim et al. 2007; Fuentes et al. 2006; Pooggin et al. 2003; Vanderschuren et al. 2007).

RNA silencing is a natural defense mechanism against viruses (Hamilton and Baulcombe 1999). It is triggered by the processing of virus-derived dsRNA by host Dicer-like (DCL) enzymes into 21- to 24-nucleotide (nt) small interfering RNAs (siRNAs) (Blevins et al. 2006; Fusaro et al. 2006). Viral siRNAs bind Argonaute (AGO) proteins and guide the resulting RNA-induced silencing complexes toward their cognate RNA molecules, leading to posttranscriptional or transcriptional silencing in the case of RNA and DNA viruses, respectively (Pooggin 2013; Schuck et al. 2013). Viral siRNAs can potentially be amplified by host RDR6 or RDR1 activities, or both, that generate dsRNA precursors of secondary siRNAs, as reported for RNA viruses (Garcia-Ruiz et al. 2010; Wang et al. 2011). Furthermore, viral siRNAs can potentially move to adjacent cells to spread the silencing effect and counteract the systemic movement of the virus. Indeed, mobile viral siRNAs have been detected in phloem exudates of virus-infected plants (Yoo et al. 2004), and cell-to-cell and long-distance movement of RNAi transgene-derived siRNAs and endogenous 21- to 24-nt siRNAs has been demonstrated in Arabidopsis (Dunoyer et al. 2010; Molnar et al. 2010). Most plant viruses including geminiviruses encode one or more silencing suppressor proteins (Csorba et al. 2015; Pooggin 2013), to the point that the outcome of most viral infections depends on the resulting balance between silencing and suppression. This balance can be shifted toward virus tolerance by overexpressing antiviral dsRNA in the form of RNA hairpins, either transiently (Pooggin et al. 2003) or from stably integrated transgenes (Bonfim et al. 2007; Fuentes et al. 2006; Montes et al. 2014; Vanderschuren et al. 2007).

It has been previously shown that RNAi-transgenic Solanum lycopersicum (variety Campbell-28) plants harboring an inverted repeat sequence from gene $C l$ of TYLCV exhibit resistance to TYLCV in greenhouse experiments (Fuentes et al. 2006). The present study was designed to test whether this RNAi-mediated resistance is durable under natural conditions of virus inoculation and whether the RNAi transgene-derived siRNAs have off-target effects on the tomato transcriptome.

\section{RESULTS}

\section{Transgenic tomato plants expressing a hairpin RNA cognate to the TYLCV $C 1$ gene are resistant to TYLCV infection under open-field conditions.}

In a previous study, kanamycin-resistant $\left(\mathrm{Km}^{\mathrm{R}}\right)$ RNAitransgenic tomato lines designed to generate siRNAs cognate to a 728-nt TYLCV C1 gene fragment from an intron-containing hairpin RNA transgene construct (Fig. 1A) exhibited resistance to TYLCV after inoculation with viruliferous whiteflies in a glass house under a natural regime of light and controlled temperature (Fuentes et al. 2006). In this study, additional transgenic lines carrying the same anti-TYLCV RNAi construct linked to a bastaresistant $\left(\mathrm{Ba}^{\mathrm{R}}\right)$ marker gene (discussed below) were constructed and tested for TYLCV resistance. In early winter to spring (the productive season for tomato), several generations of tomato plants obtained from two selected transgenic lines (the previously described $\mathrm{Km}^{\mathrm{R}}$ line 126 , designated here as $\mathrm{T} 1$, and the newly generated $\mathrm{Ba}^{\mathrm{R}}$ line $\mathrm{B} 1$, designated here as T2) did not develop symptoms of viral infection. However, that work did not examine whether the asymptomatic phenotype of the transgenic plants would be maintained in a more aggressive environment, for example, under the high temperature and humidity of the summer, with large populations of viruliferous whiteflies feeding on different weeds, garden plants, and crop plants, such as soybean, beans, pepper, and tomato. To address this issue, the transgenic and control nontransgenic (designated C) tomato plants were cultivated in a field during the summer season of 2011, following normal agricultural procedures (including hand weeding and irrigation) but exposing them to natural inoculation by endemic, viruliferous whitefly populations without implementing protective practices such as the application of insecticides or pesticides. After the first month of cultivation, the plants were analyzed for the appearance of TYLCV disease symptoms, and this analysis was repeated every two weeks until most of the control plants exhibited symptoms corresponding to high severity grades of TYLCV disease, as described earlier (Friedmann et al. 1998; Lapidot and Friedmann 2002). Simultaneously with the analysis of TYLCV disease symptoms, the accumulation of viral DNA in the upper leaves was quantified by dot blot hybridization, using radioactively labeled TYLCV intergenic region (IR) DNA as a probe and a standard curve of the cloned TYLCV genomic DNA (Fig. 1E; Supplementary Fig. S1). After three months, all the control tomato plants developed disease symptoms with severity grades ranging from 2 to 4 as a result of the high prevalence and uniform distribution of infectious whiteflies in the experimental area. The accumulation of viral DNA in the control plants ranged from 0.5 to $10 \mathrm{ng}$ per sample and correlated well with disease severity. In contrast, most of the transgenic tomato plants remained symptomless, with only a few transgenic individuals exhibiting yellowing of the upper leaves to some degree. These low-grade symptomatic plants (grade $=1$ ) as well as some of the remaining symptomless plants (grade $=0$ ) accumulated viral DNA in amounts ranging from 0.05 to $0.5 \mathrm{ng}$. Twenty-one of 26 siblings of the transgenic line T1 and five of 14 siblings of the transgenic line $\mathrm{T} 2$ did not have detectable levels of viral DNA and did not exhibit symptoms of the disease at all. These results confirm and extend the previous findings on TYLCV resistance for the transgenic line T1 under greenhouse conditions (Fuentes et al. 2006).

\section{Some of the symptomless RNAi transgenic plants in the field contained a novel recombinant begomovirus.}

Our finding that several symptomless transgenic plants scored positive in the dot-blot hybridization analysis suggested a somewhat weakened antiviral effect of the RNAi transgene under field conditions, allowing for some TYLCV replication and spread, although not enough for the appearance of disease symptoms. Alternatively or additionally, a different DNA virus sharing nucleotide sequence homologies with the IR of TYLCV could be present in those transgenic plants. To test the latter hypothesis, total DNA from several control and transgenic plants was analyzed by rolling circle amplification (RCA) followed by cloning and sequencing of the amplified viral DNA. The RCA products were digested with SacI (single site in the TYLCV genome) and were analyzed by $1 \%$ agarose gel 
electrophoresis. The DNA samples from the four T2 (but not four T1) transgenic plants and all three control plants yielded approximately $2.8-\mathrm{kb}$ products, corresponding to the expected size of TYLCV $(2.78 \mathrm{~kb})$ and other begomoviruses. For the control plants, additional products of approximately $1.3 \mathrm{~kb}$ were obtained. Cloning and sequencing of the resulting RCA products from two of the control plants revealed that the $2.8-\mathrm{kb}$ species corresponded to the full-length TYLCV genome with 98.8 to $99 \%$ nucleotide identity to TYLCV-Cuba (National Center for Biotechnology Information [NCBI] GenBank accession AJ223505). The shorter RCA products corresponded to TYLCV genome-derived defective DNAs ranging in size from 1,216 to $1,318 \mathrm{bp}$, in which a large region of the TYLCV genome spanning the $V I$ and $C 3$ genes (positions 193 to 1,551)
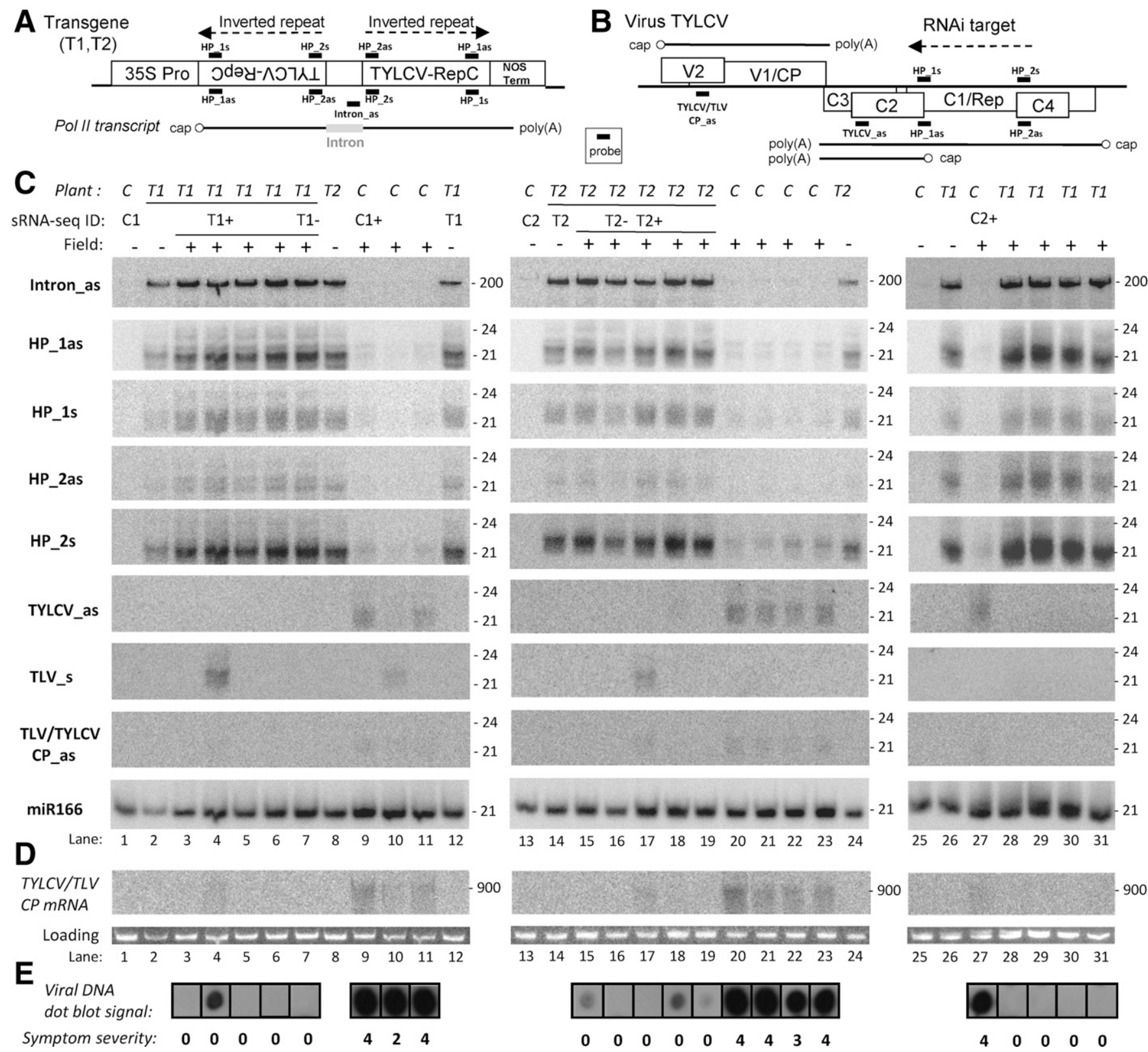

$\begin{array}{llllllllllll}13 & 14 & 15 & 16 & 17 & 18 & 19 & 20 & 21 & 22 & 23 & 24\end{array}$
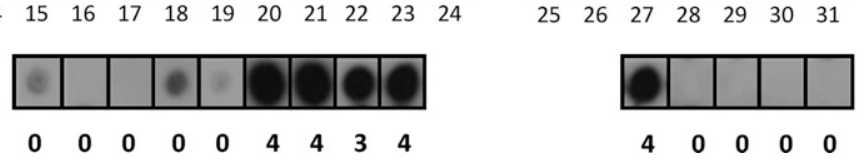

Fig. 1. Blot hybridization analyses of RNA interference (RNAi) transgene- and virus-derived small RNAs and viral DNA under greenhouse and open-field conditions. A and B, Schematic showing the Cauliflower mosaic virus $35 \mathrm{~S}$ promoter-driven hairpin RNA expression cassette of the T1 and T2 transgenes and the genome organization of Tomato yellow leaf curl virus (TYLCV). The 35S promoter, TYLCV Rep/C1 inverted repeat, castor bean catalase intron, and nopaline synthase terminator sequences (A) as well as open reading frames of the viral genes (B) are boxed and named, with the position and orientation of the transgenic TYLCV sequences and the RNAi target region in the virus genome indicated as dotted lines and the capped and polyadenylated Pol II transcripts derived from the transgene and the virus depicted as solid lines. Positions of the transgene and virus-specific sense and antisense probes used for RNA blot hybridization are indicated with short solid lines. C, RNA blot hybridization using 15\% polyacrylamide gel electrophoresis of total RNA isolated from RNAitransgenic (lines T1 and T2) and nontransgenic control (C) tomato plants. The membranes were successively hybridized with sense (s) and antisense (as) DNA oligonucleotide probes specific for the catalase intron (Intron_as), the TYLCV inverted repeat/RNAi target sequences (HP_1as, HP_1s, HP_2as, HP_2s), TYLCV (TYLCV_as), Tomato latent virus (TLV_s), both viruses (TLV/TYLCV CP_as), and 21-nucleotide (nt) endogenous tomato miRNA (miR166). The latter serves as an internal control for the three blots. The nt sizes are indicated on each data image. The samples additionally analyzed by small (s)RNA deepsequencing (namely, $\mathrm{C} 1, \mathrm{~T} 1, \mathrm{~T} 1-, \mathrm{T} 1+, \mathrm{C} 1+, \mathrm{C} 2, \mathrm{~T} 2, \mathrm{~T} 2-, \mathrm{T} 2+$, and $\mathrm{C} 2+$ ) are indicated with 'sRNA-seq ID'. D, RNA blot hybridization analysis of the viral coat protein (CP) transcripts (TYLCV/TLV CP mRNA). The cropped upper parts of the membranes from the three blots from panel C are shown hybridized with the TLV/TYLCV CP_as probe, with the approximate size (900 nt) of the CP mRNA indicated on each image; the loading controls (ribosomal RNA species) for each blot are shown below. E, Viral DNA dot blot hybridization analysis and symptom severity scores of the field-inoculated plants from panels C and $\mathrm{D}$, lanes 3 to 7,9 to 11,15 to 23 , and 27 to 31 . 
is circularized and interrupted with short deletions (positions 940 to 950) and, in most cases, with short insertions of TYLCV sequences (positions 43 to 148 or 1,352 to 1,445 ) at the circularization site. Cloning and sequencing of the RCA product from one of the $\mathrm{T} 2$ transgenic plants revealed a novel virus, for which we propose the name Tomato latent virus (TLV), based on the lack of visible disease symptoms and the low titer of viral DNA. Phylogenomic analysis showed that TLV is a product of recombination between TYLCV and a begomovirus most closely related to Sida golden mottle virus (SGMoV; GU997691) and Corchorus yellow spot virus (CYSV; DQ875868). Indeed, the 2,746-nt TLV genome is composed of a 1,080-nt region derived from TYLCV (spanning $V 2$ and $V 1 / C P$ genes from the nonanucleotide sequence at the origin of replication to position 1,072 and $98.7 \%$ identical to the corresponding region of TYLCV-Cuba) and a 1,666-nt region containing $C 1, C 4, C 2$, and $C 3$ genes derived from a virus that is $90.3 \%$ identical to SGMoV and $90.5 \%$ identical to CYSV.

In order to confirm these findings, 14 additional symptomless transgenic plants of $\mathrm{T} 1$ and $\mathrm{T} 2$ lines were subjected to blot hybridization analysis of viral CP transcripts and deep sequencing of small (s)RNAs, which detected the presence of TLV in two individuals (Fig. 1D; discussed below). Since TLV was detected only in a small number of plants, we assume that this begomovirus was transmitted by the viruliferous whiteflies present in the field and these infected plants, thus, represent de novo infections. The accumulation of TLV in RNAi-transgenic plants expressing TYLCV Cl gene-specific siRNAs is consistent with the known sequence specificity of siRNA-directed RNAi mechanisms, which, in this particular case, would target TYLCV but not TLV. Indeed, the siRNA target regions of TYLCV and TLV share only $62.3 \%$ sequence identity and their SNPs (singlenucleotide polymorphisms) are almost evenly distributed along their entire length, so that there is no stretch of nucleotide identity longer than $17 \mathrm{nt}$ (Supplementary Text S1A).

Our initial comparative study of the TLV and TYLCV partial dimer clones, using the agroinoculation method, revealed that TLV exhibits low infectivity and develops largely symptomless infections in both tomato and Nicotiana benthamiana plants under our experimental conditions. In systemically infected plants, TLV accumulates at lower levels than TYLCV, as revealed by an analysis of viral DNA by Southern blotting (Supplementary Fig. S2).

\section{The production of highly abundant siRNAs from the hairpin RNA transgene explains the high resistance to TYLCV infection.}

The accumulation of transgene- and virus-derived siRNAs was first analyzed by sRNA blot hybridization using 42-nt probes complementary to the sense (s) or antisense (as) strands of the $5^{\prime}$ and $3^{\prime}$ termini of the hairpin arms (HP_1 and HP_2, respectively [Fig. 1A and $\mathrm{B}$, for positions of the probes on the transgene and the virus maps]). The samples consisted of total RNA from transgenic and control plants infected on the field as well as from noninfected plants grown under controlled (greenhouse) conditions (Fig. 1C), and a probe for an endogenous tomato miRNA (miR166) was used as an internal control in order to normalize and compare the accumulation of virus- and transgene-derived siRNAs. The analysis revealed the presence of highly abundant transgene-derived TYLCVspecific siRNAs of both sense and antisense polarities in the transgenic plants of both the T1 and T2 lines, ranging in length from 20 to $25 \mathrm{nt}$, although the most abundant species were $21 \mathrm{nt}$ long (Fig. 1C) (note that the sRNA species cannot be accurately sized by RNA blot hybridization, so the data must be further validated by sequencing, discussed below). Compared with the transgenic (T1 and T2) plants, the control plants infected on the field accumulated much less abundant virus-derived siRNAs corresponding to the TYLCV sequence contained in the transgene (Fig. 1C). Notably, the catalase intron-specific probe detected in the transgenic (but not in control) plants an abundant long RNA species of approximately $200 \mathrm{nt}$, corresponding to the spliced intron (Fig. 1C, Intron_as). This indicates that the transgene transcript is spliced before it folds back to form the hairpin RNA precursor of siRNAs and the spliced intron RNA is not degraded.

Using a TYLCV-specific probe that does not hybridize to transgene or TLV sequences, it was possible to demonstrate that virus-derived TYLCV siRNAs are found only in nontransgenic control plants grown under field conditions and are not found in open-field transgenic plants or in noninoculated control and transgenic plants from the greenhouse (Fig. 1C, TYLCV_as). Using a TLV-specific probe that does not hybridize to TYLCV reveals, on the other hand, the presence of TLV-derived siRNAs in one of the nine T1 transgenic plants, one of the five T2 transgenic plants, and one of the eight control plants from the field. No TLV-derived siRNAs were detected in noninoculated greenhouse plants (Fig. 1C, TLV_s, lanes 1, 2, 8, 12 to 14, and 24 to 26). These results confirmed that all the analyzed transgenic plants were resistant to TYLCV, but some of them were susceptible to TLV under open-field conditions in the presence of both viruses. Further supporting this conclusion, long RNA blot hybridization analysis revealed that only the two TLV siRNA-positive transgenic plants but not other transgenic plants contained detectable amounts of viral CP mRNA of the expected size (approximately $900 \mathrm{nt}$ ) (Fig. 1D [note that the CP gene sequence is $99.8 \%$ identical between the TLV and TYLCV genomes, and the probe "TYLCV/TLV CP_as" used for this analysis could, therefore, hybridize to the $\mathrm{CP}$ transcripts derived from both TLV and TYLCV]).

To obtain a more accurate picture of sRNA identities, quantities, and profiles under different conditions, we deepsequenced sRNA populations from selected greenhouse (not infected) and field-inoculated plants corresponding to the control nontransgenic tomato and the $\mathrm{T} 1$ and $\mathrm{T} 2$ transgenic lines, which had previously scored either negative $(-)$ or positive $(+)$ for viral infection in the blot hybridization assay (Fig. 1). A total of 10 sRNA libraries were prepared and sequenced, corresponding to the healthy control $(\mathrm{C} 1$ and $\mathrm{C} 2)$ and transgenic (T1 and $\mathrm{T} 2)$ plants from the greenhouse and the field-inoculated control (TYLCV-infected: $\mathrm{C} 1+$, and $\mathrm{C} 2+$ ) and transgenic (noninfected: T1- and T2-; and TLV-infected: T1+ and T2+) plants. For each library, the resulting sRNA reads were mapped to the tomato genome, the transgene, the TYLCV genome, and the TLV genome reference sequences, using the bioinformatic tools described below. Using the "siRomics" approach (Seguin et al. 2014a), we de novo reconstructed and verified the master genomes of TYLCV and TLV present in the control $(\mathrm{C} 1+$ and $\mathrm{C} 2+)$ and the transgenic $(\mathrm{T} 1+$ and $\mathrm{T} 2+)$ plants from the resulting viral siRNA sequences and, then, remapped sRNAs with zero mismatches to the consensus master genome sequences of the TYLCV isolates (designated TYLCV-C1 and TYLCV-C2, respectively) and TLV (TLV-T1 and TLV-T2, respectively). The master genome sequences of the two isolates, which differ by 19 (TYLCV) and 11 (TLV) SNPs that do not affect the integrity of open reading frames or other known cis elements, were deposited in the NCBI GenBank database (accessions KM926623 for TLV-T1, KM926624 for TLV-T2, KM926625 for TYLCV-C1, and KM926626 for TYLCV-C2). The results of the bioinformatics analysis are illustrated in Figures 2, 3, and 4.

The total number of reads in the 10 sRNA libraries ranged from 11 to 31 million and, in each library, the majority of reads fall within a 20- to 25-nt size range, with major peaks being 21-, 22-, and 24-nt reads (Supplementary Dataset S1). We therefore restricted further bioinformatics analyses to the 20- to 25-nt 

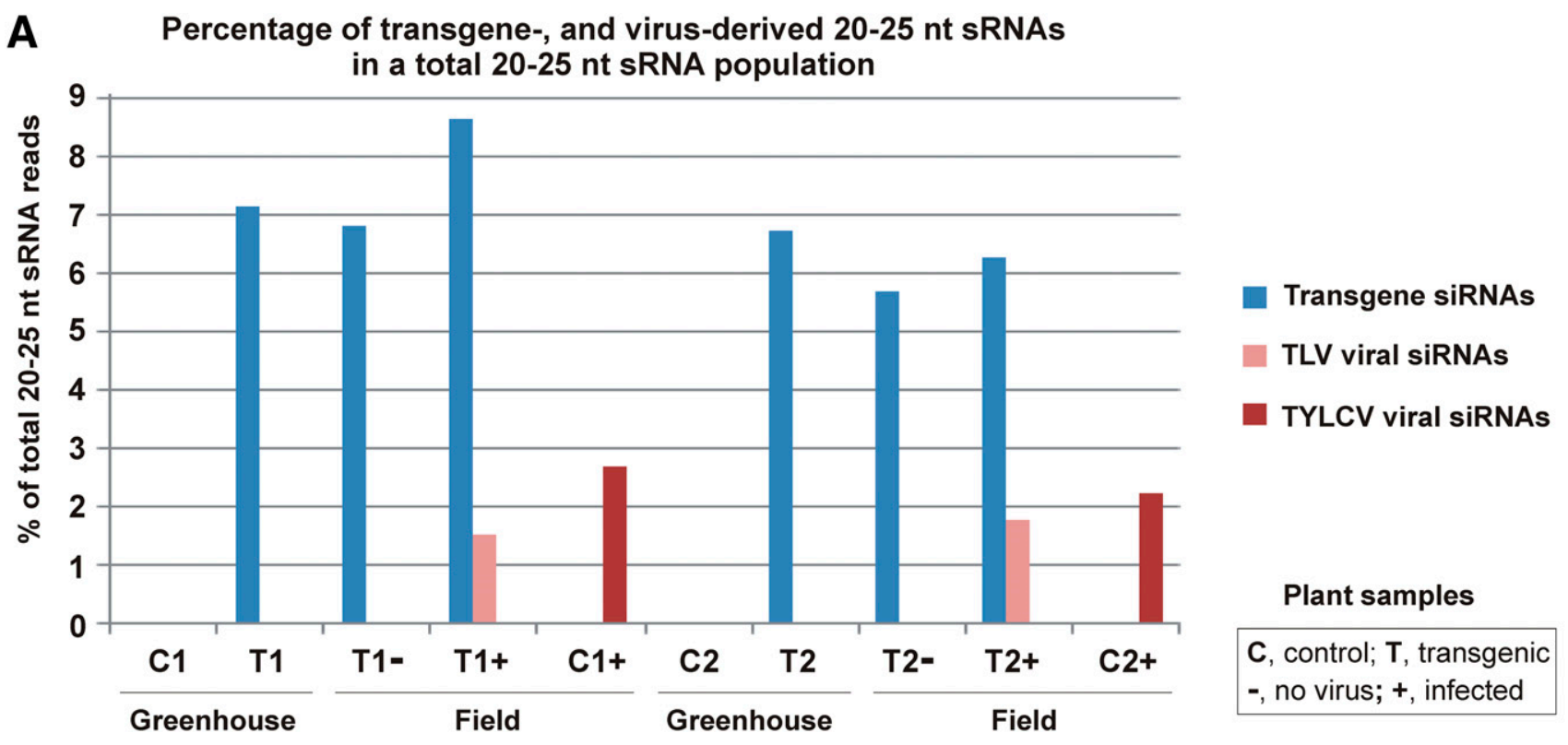

B Percentage of 20-nt, 21-nt, 22-nt, 23-nt, 24-nt and 25-nt sRNAs in total 20-25 nt sRNA populations of the endogenous, transgene and viral sRNAs
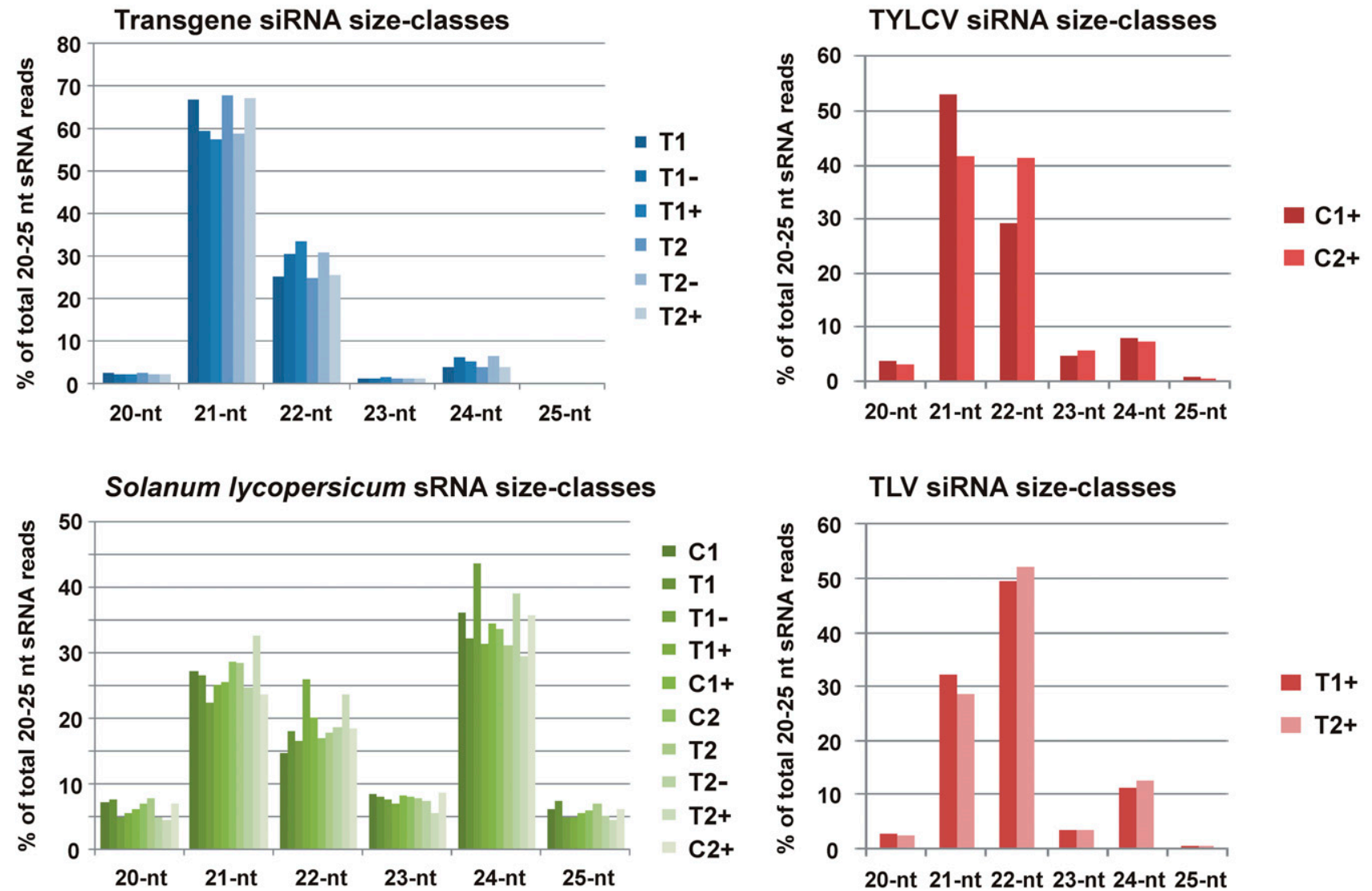

Fig. 2. Illumina sequencing counts of endogenous, transgenic, and viral small RNAs in transgenic and nontransgenic control tomato plants. A, The graph shows the percentages of transgene- and virus-derived small (s)RNAs that mapped to the transgene (T1 or T2) and the virus (Tomato latent virus [TLV] or Tomato yellow leaf curl virus [TYLCV]) genome reference sequences with zero mismatches, in the pool of total 20- to 25-nt reads from the greenhouse (noninoculated) and field-inoculated tomato transgenic (T1, T1-, T1+, T2, T2-, T2+) and control $(\mathrm{C} 1, \mathrm{C} 1+, \mathrm{C} 2, \mathrm{C} 2+)$ plants. For the field-inoculated plants, "--" stands for noninfected and "+" for virus-infected plants. B, The graphs show the percentages of each size class for 20- to 25-nt transgene- (T1, T2), virus- (TYLCV, TLV), and tomato genome-derived sRNA reads, mapped to the corresponding reference sequence of the transgene, the TYLCV genome, the TLV genome, or the tomato genome with zero mismatches. 
size range known to be populated by plant endogenous miRNAs and siRNAs as well as viral siRNAs.

In the transgenic greenhouse-grown plants, 20- to 25-nt siRNAs matching the transgene reference sequence with zero mismatches constituted $7.1 \%$ (in T1) and $6.8 \%$ (in T2) of the total population of 20- to 25-nt sRNAs (Fig. 2A). Under openfield conditions, the accumulation of transgene-derived siRNAs in noninfected plants was slightly lower for both transgenic lines (6.8\% in T1- and 5.7\% in T2-) but was slightly increased in the presence of TLV (8.6\% in T1+ and 6.3\% in T2+) (Fig. 2A). Thus, both the T1 and T2 transgenes stably express high and comparable levels of siRNAs under greenhouse and field conditions. This finding validates our blot hybridization analysis showing comparable levels of transgenic siRNAs in several biological replicates for the T1 and T2 lines under both conditions (Fig. 1C). In the field-inoculated control plants, viral siRNA reads matching the TYLCV genome with zero mismatches constituted $2.7 \%(\mathrm{C} 1+)$ and $2.2 \%(\mathrm{C} 2+)$ of the 20 - to 25-nt sRNA population. Thus, siRNAs derived from the entire $2.8 \mathrm{~kb}$ virus genome in tomato plants severely infected with

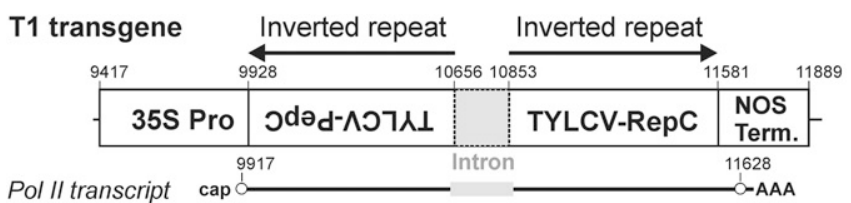

20-25 nt siRNAs in T1
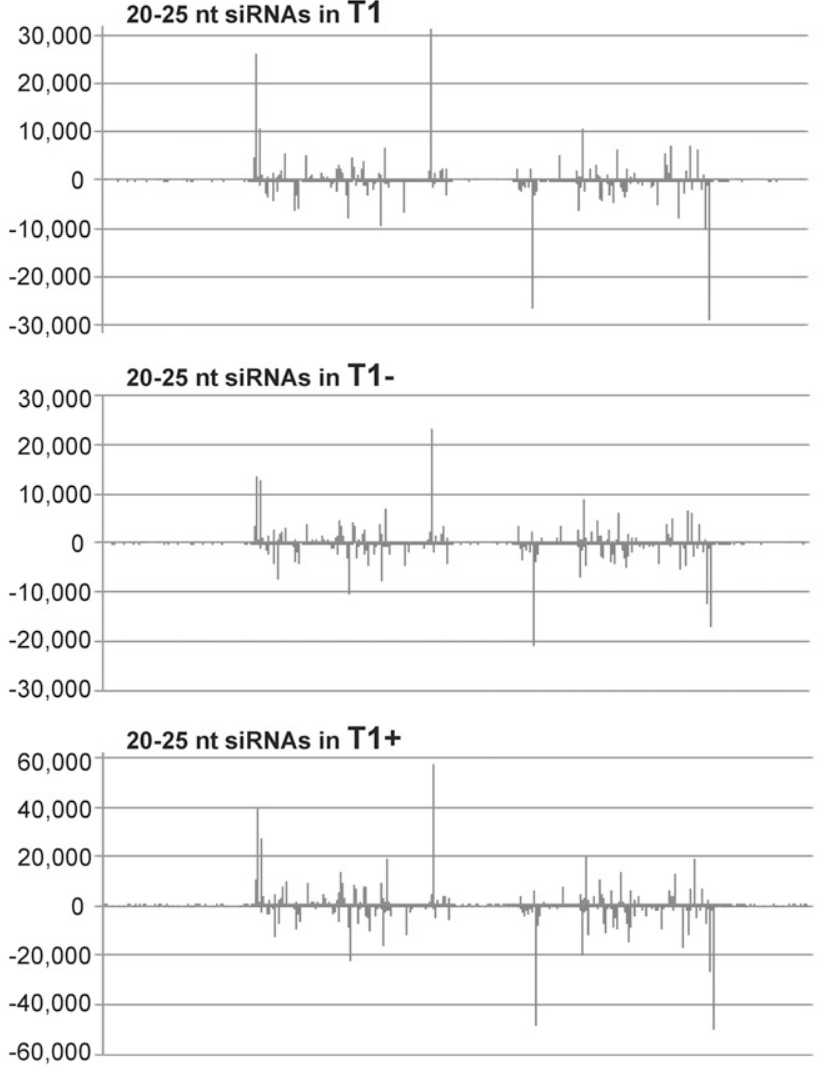

TYLCV are three times less abundant than siRNAs derived from the 0.7-kb TYLCV C1 inverted repeat sequences in the transgenic tomato plants. This massive production of transgenic siRNAs targeting TYLCV may account for the observed resistance of the transgenic plants to infection with this virus.

Notably, TLV-derived siRNAs accumulating in the transgenic plants were only slightly less abundant than TYLCVderived siRNAs in the control plants $(1.5$ and $1.8 \%$ of the total 20- to 25-nt sRNA population in $\mathrm{T} 1+$ and $\mathrm{T} 2+$, respectively [Fig. 2A]). Viral sRNA analysis using the $C 1, C 4, C 2$, and $C 3$ regions of TLV and TYLCV as reference sequences for sRNA mapping with zero mismatches confirmed that the transgenic plants T1+ and T2+ were infected with TLV but not TYLCV, whereas the control plants $\mathrm{C} 1+$ and $\mathrm{C} 2+$ were infected with TYLCV but not TLV (Fig. 2A).

\section{Mechanistic details of the biogenesis and function of transgenic and viral siRNAs.}

An analysis of the size profile of those sRNAs with perfect matches to the reference genomes employed in this work (Fig. 2B)
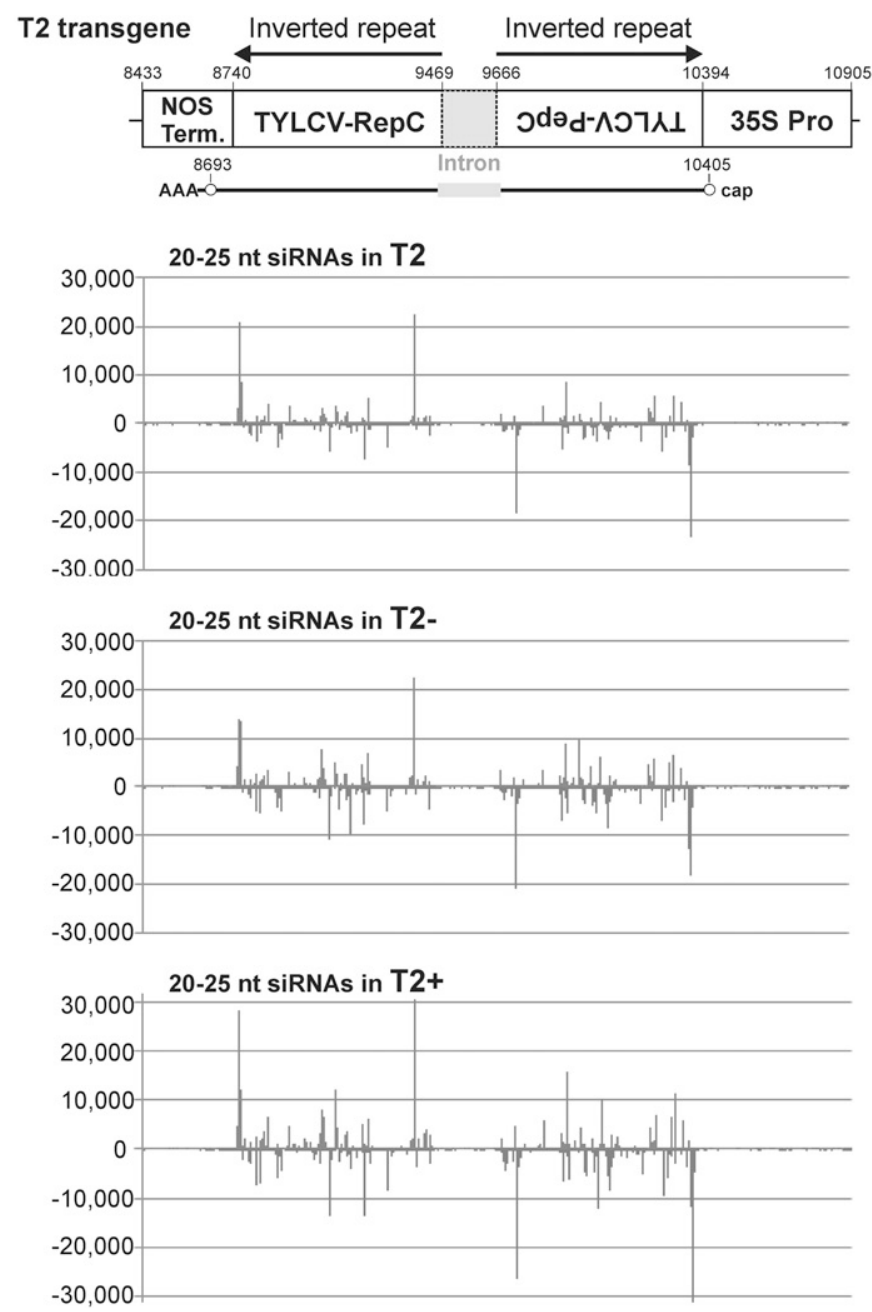

Fig. 3. Single-nucleotide resolution maps of transgene-derived 20- to 25-nt small interfering (si)RNAs in healthy control and field-inoculated RNA interference-transgenic tomato lines T1 and T2. Small (s)RNA populations from healthy controls (T1, T2) and the field-inoculated virus-free (T1-, T2-) and Tomato latent virus-infected (T1+, $\mathrm{T} 2+)$ transgenic plants were mapped to the $\mathrm{T} 1$ and $\mathrm{T} 2$ transgene reference sequences with zero mismatches and maps of 20 to 25-nt transgene-derived sRNAs were created using MISIS. The histograms plot the number of 20- to 25-nt transgene-derived sRNA reads at each nucleotide position of the 2,472-bp transgene expression cassette. Bars above the axis represent sense reads starting at each respective position; those below represent antisense reads ending at the respective position. The organization of the transgene expression cassettes is shown schematically above the histograms, with the Cauliflower mosaic virus $35 \mathrm{~S}$ promoter, the Tomato yellow leaf curl virus (TYLCV) Rep/C1 gene inverted repeats with the intervening catalase intron and the nopaline synthase terminator sequences boxed and their nucleotide positions with respect to the binary vector reference sequence indicated. The predicted Pol II transcripts are shown as solid lines, with the nucleotide positions of cap and poly(A) tail indicated. The positions and orientations of the TYLCV sequences forming the double-stranded RNA precursor of siRNAs are indicated with solid lines with arrowheads. 
revealed that 24-nt species constituted the most abundant endogenous tomato sRNA, followed by $21-$ and $22-n t$ species. In contrast, the population of transgene-derived siRNAs was dominated by $21-n t$ species, followed by much less abundant (two- to threefold) 22-nt species and severely underrepresented 24-nt species (Fig. 2B). This indicates that the hairpin dsRNA precursor of transgene-derived siRNAs is processed predominantly by tomato homologs of the Arabidopsis DCL4 and DCL2, which normally generate 21- and 22-nt endogenous and viral siRNAs (Blevins et al. 2006; Fusaro et al. 2006). A tomato homolog of the Arabidopsis DCL3 that generates 24-nt siRNAs in the nucleus, reviewed by Pooggin (2013), appears to process only a small fraction of the hairpin RNA, likely because the latter is efficiently transported to the cytoplasm following the splicing event. Interestingly, the size profile of TYLCV-derived viral siRNAs resembles that of transgene-derived siRNAs, although the 21-nt viral siRNAs are somewhat less predominant. In contrast, TLV-derived viral siRNAs are dominated by 22 -nt species, followed by 21 - and 24-nt species (Fig. 2B). TLV infection affected only slightly the size profiles of endogenous sRNAs and transgene-derived siRNAs. Likewise, TYLCV infection did not drastically affect the size profile of endogenous sRNAs (Fig. 2B), although the possibility that virus infection might have an impact on some specific tomato miRNAs and siRNAs cannot be discarded.

An analysis of single-nucleotide resolution maps of transgenederived siRNAs revealed that, in all six transgenic plants, 20- to

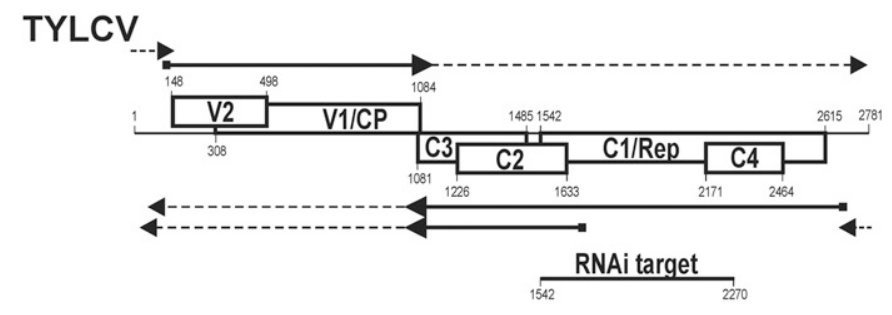

TYLCV-C1 siRNAs in C1+

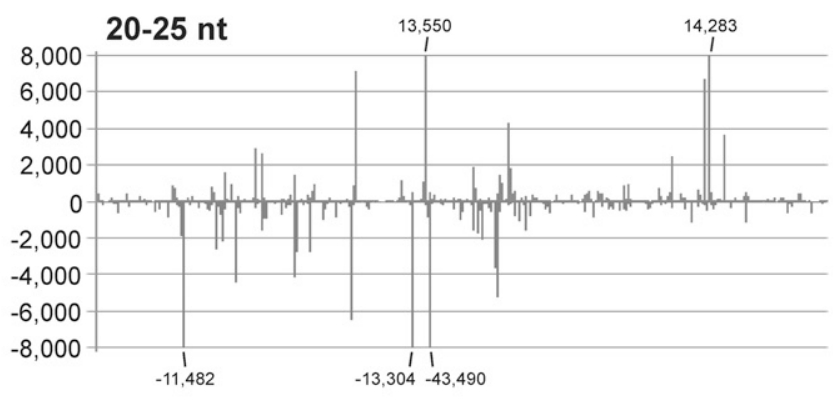

TYLCV-C2 siRNAs in C2+

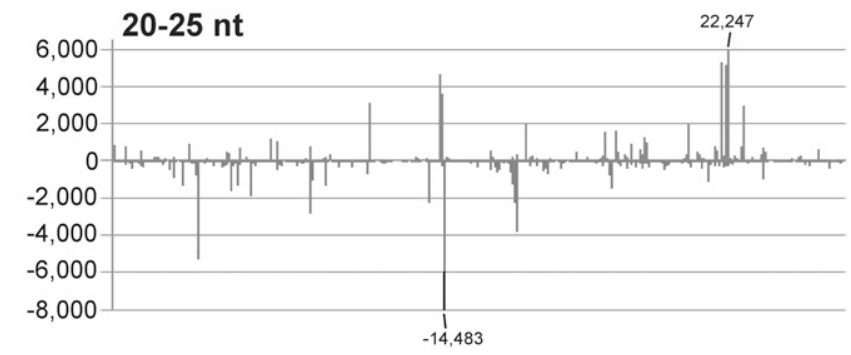

25-nt siRNAs are derived almost exclusively from TYLCV sequences and that the hotspots for siRNA biogenesis are not located in the promoter, intron, or terminator regions (Fig. 3). The fact that only a few sRNA reads are derived from the promoter explains the robust siRNA expression observed under greenhouse and open-field conditions and indicates that transgenederived siRNAs are not generated from regions outside the repeated TYLCV sequences, which otherwise would have resulted in transcriptional silencing of the transgene. Furthermore, only primary siRNAs appear to be produced from the hairpin RNA transcript. Indeed, only a few reads map to the $5^{\prime}$ - and $3^{\prime}$ terminal sequences of the transcript, which are not involved in formation of the hairpin dsRNA secondary structure or to the intron sequence (Fig. 3), indicating that RDR-dependent siRNA amplification does not operate efficiently on the transgenic transcript. Remarkably, the pattern of siRNA hotspots along the inverted repeat sequences in both sense and antisense orientation does not differ substantially between the transgenic lines and for each transgenic line under the three examined conditions, i.e., greenhouse, open field, and TLV infection on the field (Fig. 3). Likewise, no substantial differences regarding hotspot patterns were found for each of the three major siRNA size classes (Supplementary Fig. S3). Thus, the mechanism of siRNA biogenesis from the hairpin RNA is remarkably reproducible in the two transgenic lines and is not substantially affected by environmental conditions or concomitant viral

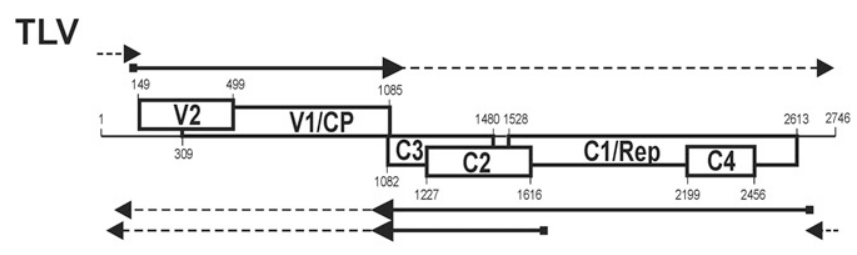

\section{TLV-T1 siRNAs in T1+}

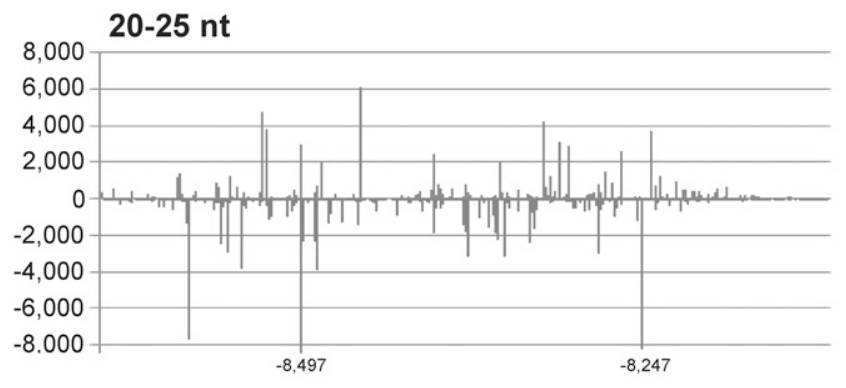

TLV-T2 siRNAs in T2+

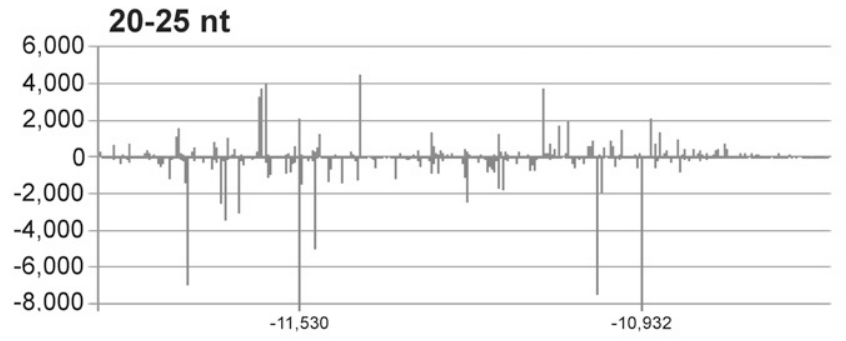

Fig. 4. Single-nucleotide resolution maps of 20- to 25-nt viral siRNAs from Tomato yellow leaf curl virus (TYLCV)-infected nontransgenic control (C1+, C2+) and Tomato latent virus (TLV)-infected transgenic (T1+, T2+) plants. The histograms plot the number of 20- to 25-nt viral small RNA reads at each nucleotide position of the 2,781-bp TYLCV and the 2,746-bp TLV DNA genomes; bars above the axis represent sense reads starting at each respective position; those below represent antisense reads ending at the respective position. The genome organization of TYLCV and TLV is shown schematically above the histograms, with four leftward $(C 1 / R e p, C 4, C 2, C 3)$ and two rightward $(V 2, V 1 / C P)$ open reading frames boxed and their nucleotide positions indicated. The predicted leftward and rightward mRNAs are shown as solid lines with arrowheads. Potential readthrough transcripts are shown as dotted lines. The RNA interference target region with its nucleotide positions in the TYLCV genome is shown as solid line. 
infections. Notably, siRNA hotspot origins differ for the three major size classes; the hottest spots occur at both ends of the hairpin for the 21-nt species, mostly at the intron end for the 22-nt species, and mostly at the overhang end for the 24-nt species. This finding might indicate that the DCLs generating the different siRNA size classes (i.e., DCL4/DCL1, DCL2, and DCL3, respectively [Fusaro et al. 2006; Blevins et al. 2006; Blevins et al. 2011]) may access or process the hairpin RNA termini with different efficiencies.

Analysis of single-nucleotide resolution maps of virus-derived siRNAs revealed that the major hotspots for the production of viral 20- to 25-nt siRNAs are located in protein-coding sequences for both the sense and antisense strands (Fig. 4). In TYLCV, the hottest spots are located at the $V 2$ and $V 1, C 2$ and $C 3$, and $C 4$ gene sequences, while the IR and the $C 1$ sequences, including the RNAi target region, spawn less abundant siRNAs. The latter finding supports our above conclusions based on RNA blot hybridization and explains the antiviral potency of hairpin RNA-derived siRNAs, which are produced in the transgenic plants in massive quantities, outnumbering low-abundance viral siRNAs produced from the corresponding region of the TYLCV genome. The pattern of siRNA hotspots in the shared portion of the TYLCV and TLV genomes ( $V 2$ and $V 1$ genes) is similar for both viruses. However, substantial differences are observed in the TLV $C 2$ and $C 3$ region, which produces relatively less abundant siRNAs, and in the TLV C1 region, which produces relatively more abundant siRNAs (Fig. 4). In both TYLCV and TLV, the siRNA hotspot patterns were unique for each of the three major size classes and these patterns were reproducibly found both in plants infected with TYLCV (C1+ and C2+) or TLV (T1+ and T2+) (Supplementary Fig. S4), supporting the above-mentioned notion that distinct DCL activities may have preferences for certain structures or sequences in viral siRNA precursors, as has been proposed for Arabidopsis DCLs (Blevins et al. 2006, 2011; Fusaro et al. 2006; Nagano et al. 2014). However, we cannot exclude an alternative explanation, which takes into account the contribution of distinct AGO proteins to the stabilization of sRNAs in a size- and sequence-specific manner, as has also been established in Arabidopsis (Mi et al. 2008; Montgomery et al. 2008; Takeda et al. 2008). In order to address the latter hypothesis, we analyzed the $5^{\prime}$ nucleotide identities of viral and transgenic siRNAs, comparing them to those of endogenous tomato sRNAs (Supplementary Dataset S1). The endogenous 21-nt sRNAs have a strong bias to $5^{\prime}$ uridine $\left(5^{\prime} \mathrm{U}\right)$, which was only slightly affected in the presence of transgene or virus (varying from 68 to $81 \%$ ). This bias is consistent with the majority of 21-nt tomato sRNAs being associated with one or more tomato homologs of Arabidopsis AGO1, which is associated mostly with 21-nt 5'U sRNAs, including most miRNAs (Mi et al. 2008; Takeda et al. 2008). The majority of 22-nt tomato sRNAs exhibit a bias to $5^{\prime}$ adenosine (5'A) (54 to $74 \%$ ) and $5^{\prime} \mathrm{U}$ (19 to $31 \%$ ), suggesting their preferential association with tomato homologs of Arabidopsis AGO2 and AGO1, respectively. The majority of 24-nt tomato sRNAs possess 5'A (69 to 79\%), similar to 24-nt heterochromatic siRNAs associated with AGO4 in Arabidopsis (Havecker et al. 2010; Mi et al. 2008; Takeda et al. 2008). The 5' nucleotide profile of transgene-derived siRNAs differs from the profile of endogenous sRNAs in that 22- and 24-nt siRNAs possess predominantly $5^{\prime} \mathrm{U}$ (68 to $86 \%$ and 47 to $60 \%$, respectively), while 22 - and 24-nt $5^{\prime} \mathrm{A}$ siRNAs are underrepresented ( 9 to $25 \%$ and 33 to $44 \%$, respectively). Nonetheless, 21-nt siRNAs, the most abundant transgenic siRNAs, are predominantly $5^{\prime} \mathrm{U}$ (55 to $71 \%$ ), similar to 21-nt tomato sRNAs. Interestingly, the profile of TYLCVderived viral siRNAs differs from the profiles of both endogenous sRNAs and transgenic siRNAs. Most notably, 21-nt 5'U siRNAs are only the second most abundant species (29 to 35\%) after 21-nt $5^{\prime}$ A siRNAs (53 to $62 \%$ ). It is tempting to speculate that highly abundant 21-nt 5'U siRNAs likely associated with AGO1 would be responsible for the potent antiviral effect of the hairpin RNA transgene. Curiously, the $5^{\prime}$ nucleotide profile of TLV-derived viral siRNAs is closer to the profile of transgene-derived siRNAs than to the profile of TYLCV-derived viral siRNAs (Supplementary Dataset S1). This finding together with relatively higher levels of 22- and 24-nt siRNAs derived from TLV (Fig. 2B) implies that the tomato silencing machinery might target TLV more efficiently than TYLCV, which would account for the symptomless phenotype of TLV infections and the severe disease caused by TYLCV infection.

Our findings that the hotspots for viral siRNA production are present on both the forward and reverse strands of TYLCV and TLV genes (Fig. 4) and that the total numbers of sense and antisense reads are almost equal (Supplementary Dataset S1) imply that viral siRNA precursors are perfectly double-stranded. For the bipartite begomovirus Cabbage leaf curl virus $(\mathrm{CaLCuV})$, such dsRNA precursors were proposed to be generated by Pol II-mediated bidirectional read-through transcription of circular viral DNA (Aregger et al. 2012). Similar to the $\mathrm{CaLCuV}$ case (Aregger et al. 2012; Seguin et al. 2014a), we found that both forward and reverse strands of the entire circular genomes of TYLCV and TLV are covered with nonredundant viral siRNAs species (maps of viral siRNAs are available in Supplementary Dataset S2). The fact that all (or most) sequences in the viral IRs are covered with viral siRNAs implies that these sequences are transcribed in both sense and antisense orientation, likely by Pol II as discussed by Pooggin (2013).

\section{Expression of the hairpin RNA alters the tomato transcriptome.}

We observed slight phenotypic and developmental abnormalities in both the T1 and T2 transgenic lines when compared with control plants (to be published elsewhere). In order to determine whether these slight abnormalities are caused by epigenetic alterations in plant gene expression following the transformation and selection procedures or by robust expression of the transgenic hairpin RNA itself, we followed a transcriptome profiling approach.

A tomato microarray platform was used to find changes in the expression levels of tomato transcripts by analyzing total RNA from both transgenic lines (the microarray data were deposited to the NCBI Gene Expression Omnibus (GEO) under accession number GSE63708). Unsupervised clustering anal$y$ sis of the genes across all the samples revealed that the replicates for each line are highly similar and that the two transgenic lines (T1 and T2) have similar and consistent expression differences relative to the control line. Two groups for comparison were further considered: $\mathrm{T} 1$ over control plants and $\mathrm{T} 2$ over control plants. Considering false discovery rate (FDR)-adjusted $P$ values smaller than 0.05 (FDR $<0.05$ ), a total of 75 genes in $\mathrm{T} 1$ plants and 233 genes in T2 plants were found to be differentially expressed (DE) over nontransgenic control plants (Fig. 5A). Such transcriptome changes in the transgenic lines might support the probable role of epigenetic modification of the plant genome during the dedifferentiation and differentiation of plant tissues required by the transformation process. The presence of larger numbers of DE genes in $\mathrm{T} 2$ plants might be related either to differences in selection conditions for the transgene (basta instead of kanamycin), effects of transgene position within the plant genome, or both. Intriguingly, a deeper analysis of DE genes in the $\mathrm{T} 1$ and $\mathrm{T} 2$ lines revealed that 70 genes were identically affected in $\mathrm{T} 1$ as well as in $\mathrm{T} 2$ over control pants, all of them expressed with the same profile and magnitude: 40 genes upregulated and 30 genes downregulated (Fig. 5C; Supplementary Dataset S3). These striking commonalities 
between the T1 and T2 lines cannot be easily explained by the above-described factors and are more simply accounted for by off-target effects of the hairpin RNA-derived siRNAs, which are shared by both transgenic events.

The main biological processes, molecular functions, and localization of the proteins affected in both transgenic lines were assigned by using Blast2GO software (Fig. 5B). It is worth noting that most DE genes could be grouped as being involved in biological regulation, stimulus response, metabolic, and cellular processes (37, 46, 51, and 43, respectively). Cell, organelle, and membrane were the main compartments in which most of the encoded proteins were found (48, 32, and 22, respectively). At the molecular level, catalytic and binding activities predominated (35 and 40 proteins, respectively). However, the contributions of all these protein attributes to the observed developmental abnormalities of $\mathrm{T} 1$ and $\mathrm{T} 2$ plants remain to be clarified. Interestingly, none of the tomato genes encoding major components of the RNA silencing machinery are affected by hairpin dsRNA expression from the transgene, suggesting that the components involved in the biogenesis and function of endogenous tomato miRNAs and siRNAs may not be saturated by the massive production of transgene-derived siRNAs.

\section{DISCUSSION}

Our findings demonstrate the stable expression of highly abundant antiviral siRNAs from an intron-containing hairpin
RNA transgene in Solanum lycopersicum lines for at least six generations under both controlled greenhouse conditions and the more aggressive conditions of the summer season in an open-field environment. Notably, this field trial exposed the RNAi transgenic plants to various abiotic and biotic stresses, including the presence of massive quantities of viruliferous whiteflies that transmitted TYLCV, TLV, and, potentially, other geminiviruses. Despite these stresses the RNAi plants stably expressed high quantities of transgene-derived siRNAs and exhibited high resistance to TYLCV disease, which severely affected neighboring nontransgenic tomato plants. The robust expression of transgenic siRNAs, which constituted approximately 6 to $8 \%$ of the total sRNA population in transgenic plants, does not appear to saturate the tomato RNA silencing machinery, as transcriptome profiling failed to reveal any changes in expression of the tomato genes that mediate RNA silencing. Further supporting this conclusion, the transgenic plants built a strong antiviral response to the recombinant geminivirus TLV by generating abundant TLV-derived siRNAs, which likely contributed to the tolerance exhibited by these plants to the virus, which was able to infect only a small fraction of the transgenic plants and did not cause severe disease symptoms.

The ability of TLV (but not TYLCV) to replicate and spread in the RNAi transgenic plants is not surprising, given the sequence-specific nature of the RNAi mechanism, which, in this case, was engineered to recognize TYLCV and TYLCV-like
A Number of differentially-expressed (DE) genes

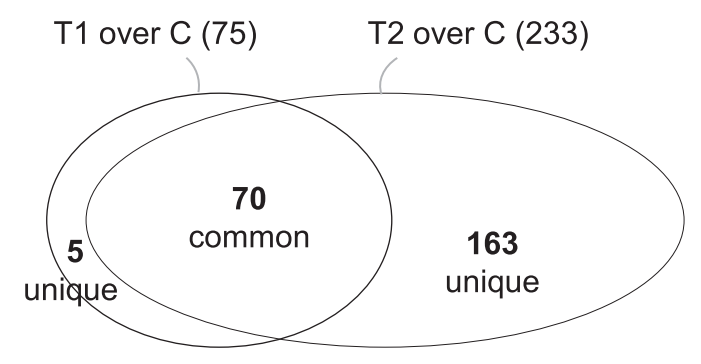

B Biological processes affected in both $T 1$ and $T 2$ lines

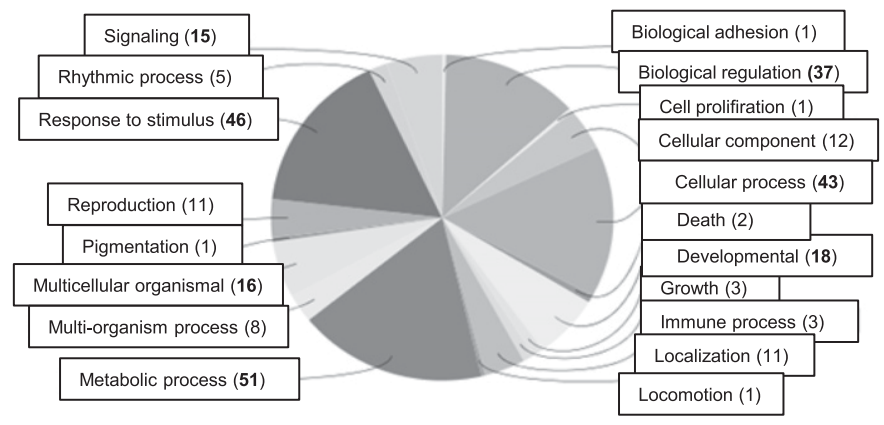

C

Log2 ratio for the 70 common DE genes in transgenic $T 1$ and $T 2$ lines over control (C) plants

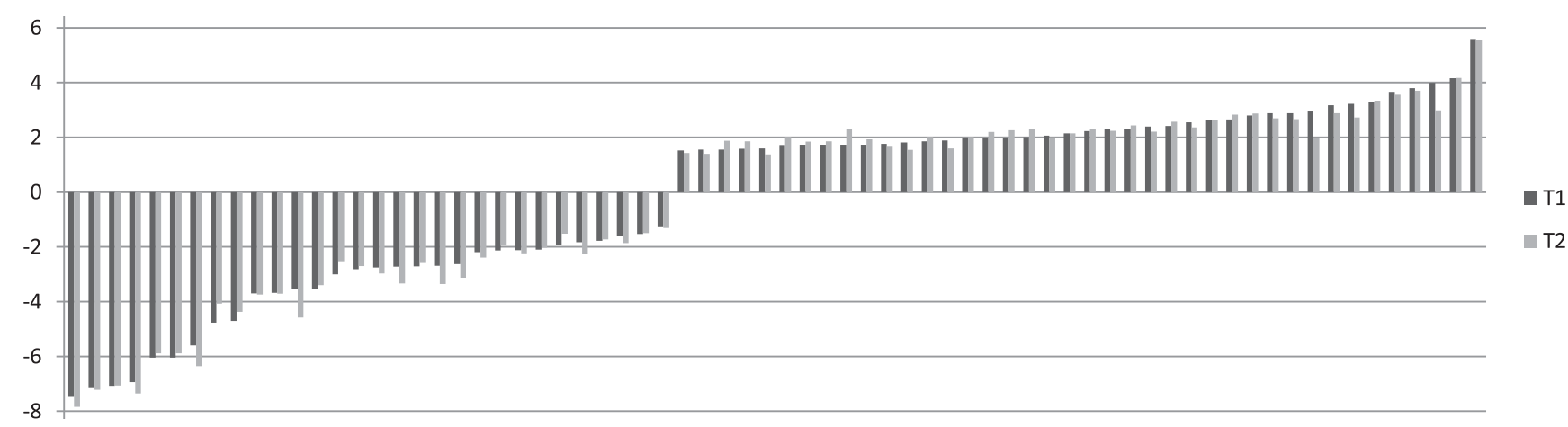

Fig. 5. Transcriptome profiling of RNA interference-transgenic lines T1 and T2 compared with control (C) nontransgenic Campbell-28 plants. A, Number of differentially expressed (DE) genes in T1 and T2 compared with control plants with a false discovery rate $<0.05$. The total numbers of DE genes in the T1 and $\mathrm{T} 2$ lines are given in brackets; the numbers of common (overlapping) and unique genes are indicated within 'T1 over C' and 'T2 over C' circles. B, Biological processes affected in both $\mathrm{T} 1$ and $\mathrm{T} 2$ lines. The pie chart shows the proportions of the common DE genes dedicated to the respective biological processes (boxed with the process name and the number of DE genes). C, Log2 ratio for the 70 common DE genes in transgenic T1 and T2 lines over control (C) plants. $\log 2$ ratio for each of the $70 \mathrm{DE}$ genes is shown along the $x$ axis with a pair of neighboring bars (dark gray for T1 over control and light gray for T2 over C). Note that $\log 2$ ratio values (on the $y$ axis) less than -1 characterize fold changes for the 30 common downregulated genes, while $\log 2$ ratio values more than +1 characterize fold changes for the 40 common upregulated genes. 
viruses sharing sequence homologies in the targeted region. Interestingly, TLV infection did not break the transgenic RNAimediated immunity to TYLCV and did not interfere with expression of the transgene-derived siRNAs. In TYLCV and other monopartite begomoviruses, the $C 2, C 4$, and $V 2$ genes have been implicated in RNA silencing suppression (Dong et al. 2003; Luna et al. 2012; Wang et al. 2014; Xie et al. 2013; Zrachya et al. 2007). Since TLV is a chimeric monopartite begomovirus that acquired the $V 2$ and $V 1$ genes from TYLCV and the $C 1, C 2$, $C 3$, and $C 4$ genes from a bipartite begomovirus, it will be interesting to conduct a comparative study of the $\mathrm{C} 2$ and $\mathrm{C} 4$ proteins from TLV and TYLCV to examine their abilities to suppress one or both RNA silencing- or innate immunitybased plant defenses (Zvereva and Pooggin 2012).

Interestingly, a non-TYLCV portion of the recombinant TLV genome is closely related to the corresponding portion of the New World begomoviruses SGMoV and CYSV with bipartite genomes, whereas TYLCV is a monopartite begomovirus originating from the Old World (most likely introduced in Cuba from the Mediterranean in the early 1990s) (Duffy and Holmes 2007; Lefeuvre et al. 2010). This implies that TLV has emerged following the arrival of TYLCV in the New World as a result of its recombination with a New World begomovirus. In the Old World, natural recombinations between TYLCV and related monopartite begomoviruses have been reported (Bananej et al. 2004; Lefeuvre et al. 2010; Navas-Castillo et al. 2000). The New World bipartite begomoviruses such as SGMoV and CYSV do not possess a V2 gene and the lack of this gene is likely compensated by a DNA-B component encoding $\mathrm{BC} 1$ and $\mathrm{BV} 1$ proteins that facilitate virus movement (Rojas et al. 2001). Since TLV has acquired $V 2$ from TYLCV, it might not need DNA-B from a parental New World begomovirus. Consistent with this hypothesis, we did not find any evidence for DNA-B in TLV-infected plants.

Viral siRNAs have previously been profiled by deep sequencing of total RNA from Solanum lycopersicum plants infected with the TYLCV-like Old World viruses Tomato yellow leaf curl China virus (TYLCCNV) (Yang et al. 2011) and Tomato yellow leaf curl Sardinia virus (TYLCSV) (Miozzi et al. 2013). In many aspects, the TYLCV siRNA profile revealed in our study is similar to that obtained for TYLCCNV, although there are differences regarding the distribution of siRNA hotspots along the genome. The observed differences in siRNA profiles between TYLCV, TYLCCNV, and TYLCSV can potentially stem from differences in the nucleotide composition of the respective regions of the viral genomes, as was observed here for nonshared regions of the TYLCV and TLV genomes (Fig. 4).

Field trials and phenotyping of two RNAi-transgenic common bean lines resistant to the New World bipartite begomovirus Bean golden mosaic virus (BGMV) have been conducted (Aragão and Faria 2009). Both lines carried a transgene driven by the Cauliflower mosaic virus $35 \mathrm{~S}$ promoter that expressed an intron-containing hairpin RNA cognate to the BGMV ACl gene (Bonfim et al. 2007), thus resembling the RNAi transgenic lines analyzed in our study. In further similarity, this transgene stably expressed anti-BGMV siRNAs (as analyzed by RNA blot hybridization [Aragão et al. 2013]) and provided immunity to BGMV infection in the field trials, albeit at lower (5 to 80\%) rates of disease incidence on control plants (Aragão and Faria 2009). Here, we extended these findings by demonstrating robust and durable resistance of anti-TYLCV RNAi transgenic tomato lines to TYLCV infection at $100 \%$ disease incidence on control plants, providing strong evidence on the applicability of the RNAi approach against geminiviruses, which has remained a point of contention (Aragão and Faria 2009; Lucioli et al. 2008; Ribeiro et al. 2007). Although the presence of RNAi transgene-derived siRNAs does not necessarily guarantee resistance to a cognate geminivirus (Ribeiro et al. 2007), other factors such as the siRNA expression level (high, as measured here in both $\mathrm{T} 1$ and $\mathrm{T} 2$ lines) and the RNAi target region within a geminivirus genome ( $\mathrm{AC} 1$ gene, as targeted here and in the BGMV study [Aragão and Faria 2009]) can contribute to antiviral immunity in RNAi-transgenic plants. The in-depth molecular analyses conducted during this work on sRNAs derived from the RNAi transgene as well as from the target (TYLCV) and nontarget (TLV) begomoviruses shed new light on the mechanisms of durable RNAi and siRNA-directed antiviral silencing in the economically important crop plant Solanum lycopersicum. Our finding that stable expression of the RNAi transgene has an impact on the plant transcriptome, accompanied with slight developmental abnormalities of the transgenic plants, illustrates the presence of a trade-off between defense and development, and highlights the convenience of an inducible RNAi approach.

\section{MATERIALS AND METHODS}

\section{Plant material.}

$\mathrm{Km}^{\mathrm{R}}$ transgenic tomato line 126 , designated here as $\mathrm{T} 1$, has been generated previously by agrobacterium-mediated transformation of Solanum lycopersicum variety Campbell-28 (Fuentes et al. 2006). The Campbell-28 variety, designated here as the control, is an early processing type tomato for dual fresh market and industrial processing purposes, characterized by determinate growth and the production of flattened fruits with a very low fruit length-to-diameter quotient. Campbell-28 was one of the main tomato varieties cultivated in Cuba until the mid-1990s when, because of its high susceptibility to TYLCV infection, it was proscribed from tomato-cultivated areas. $\mathrm{Ba}^{\mathrm{R}}$ transgenic tomato line $\mathrm{B} 1$, designated here as $\mathrm{T} 2$, was generated by subcloning a HindIII fragment containing the RNAi hairpin expression cassette from T1 (Fuentes et al. 2006) into the pCambia 3300 binary vector (carrying the phosphinothricin acetyl transferase marker gene for selection with basta), transforming the resulting construction into Campbell-28 tomato by agrotransformation, as described in detail by Fuentes et al. (2008). Line T2 was selected on the field from several transgenic lines based on TYLCV resistance. The fourth self-pollinated generation of $\mathrm{Ba}^{\mathrm{R}}$ plants of the line $\mathrm{T} 2$ and the sixth self-pollinated generation of $\mathrm{Km}^{\mathrm{R}}$ plants of the line $\mathrm{T} 1$ were used for the openfield and greenhouse (glass house) experiments described here. Five siblings, each, from transgenic lines T1 (designated km-1 through $\mathrm{km}-5$ ) and T2 (B-1 through B-5) and six siblings from the nontransgenic control Campbell-28 tomato (wt-1 through wt-6) grown in the glass house were used for further molecular analysis. In the field experiment, $26 \mathrm{~T} 1$ plants (ikm-1 through ikm-17), 14 T2 plants (iB-1 through iB-14), and 18 control plants (iwt-1 through iwt-18) were used for further molecular analysis.

\section{Conditions for the cultivation of tomato plants and virus inoculation.}

Tomato plants were germinated in an insect-proof glass house under controlled conditions $\left(25^{\circ} \mathrm{C}, 70 \%\right.$ relative humidity) and a natural light regime. A 1:1 mixture of peat Terraplant 2 (COMPO GmbH and Co. KG) and zeolite Litosand (natural product Tasajeras, Empresa Geominera del Centro) was used for germination in pots. One month after germination, the plants that had reached a four-leaf stage were transplanted to a field area near Havana city in row plantation (17 plants per row) and were cultivated from June to September 2011, under license CH47-L(104)09 of Centro Nacional de Seguridad Biológica. Temperatures on the field ranged from 25 to $32^{\circ} \mathrm{C}$. Both nontransgenic control plants and transgenic T1 and T2 plants were cultivated for four months under these open-field conditions. The development of disease symptoms was analyzed every 
two weeks. When all the control nontransgenic plants had developed severe TYLCV disease symptoms (grade 3 or 4 on the symptom severity grade scale described in [Friedmann et al. 1998; Lapidot and Friedmann 2002]), samples were collected from the top leaves of both transgenic and nontransgenic plants and approximate titers of viral DNA were determined by dot-blot hybridization using an $\left[\alpha-{ }^{32} \mathrm{P}\right] \mathrm{dATP}-$ labeled probe prepared by a random primer procedure as described in detail previously (Fuentes et al. 2006). The probe spanned $500 \mathrm{nt}$ of the TYLCV genome, including the IR and the $5^{\prime}$ region of gene $\mathrm{C} 1$ and could, therefore, hybridize to the 160-bp portion of the TLV IR (from the nonanucleotide sequence to the V2 start codon), which is nearly identical between the TLV and TYLCV genomes.

\section{RCA of circular viral DNA from inoculated tomato plants.}

Total DNA was extracted from the upper leaves of the plants by the CTAB method as described by Doyle and Doyle (1990). For RCA of the geminivirus genomes, $\phi 29$ polymerase was used according to the instructions of the Illustra Templiphi100 amplification kit (GE Healthcare Life Sciences) with some modifications. Briefly, $50 \mathrm{ng}(1 \mu \mathrm{l})$ of total DNA were mixed with $1.5 \mu \mathrm{l}$ of $\mathrm{H}_{2} \mathrm{O}$ and $5 \mu \mathrm{l}$ of sample buffer. The mixture was heated at $94^{\circ} \mathrm{C}$ for $5 \mathrm{~min}$ and was allowed to cool on ice. Afterward, $5 \mu \mathrm{l}$ of the reaction buffer and $0.2 \mu \mathrm{l}$ of $\phi 29$ polymerase were added to a final volume of $12.7 \mu \mathrm{l}$ and the resulting reaction was incubated at $28^{\circ} \mathrm{C}$ for 16 to $18 \mathrm{~h}$. The reaction products were digested with SacI (New England Biolabs) and were visualized on 1\% agarose gels. The linear DNA bands were excised from the gel, were cloned into plasmid pBluescriptIIKS/SK(+), and were sequenced.

\section{Construction and testing of TLV and TYLCV infectious clones.}

The TYLCV infectious clone was constructed previously as a viral genome dimer in the pGJ357 binary vector (Fuentes et al. 2009). In order to generate a TLV infectious clone, the TLV-T2+ genome was digested with $\mathrm{SacI}$ and was cloned into the $\mathrm{SacI}$ site of pUC19 to obtain pUC19-TLV (note that sequencing of this clone revealed a single nucleotide substitution at position 2,484, T-to-A, compared with the consensus master genome sequence of TLV-T2 deposited in GenBank). pUC19-TLV was digested with BamHI and SacI to generate a fragment comprising the IR and $5^{\prime}$ end of $C 1$, which was cloned into the BamHI and SacI sites of the binary vector pCambia 3300 to generate pCambia 3300-IRTLV. Finally, the TLV genome digested with $S a c$ I was cloned into the SacI site of pCambia 3300-IRTLV, and a head-to-tail clone was selected representing a partial dimer of the TLV genome. Both TYLCV and TLV partial dimer-containing binary vectors were mobilized to Agrobacterium tumefaciens LBA4404 for plant inoculation.

Tomato (Solanum lycopersicum variety Campbell-28) and Nicotiana benthamiana plants were grown until the four-leaf stage in pots with a 1:1 mixture of peat Terraplant 2 (COMPO $\mathrm{GmbH}$ and $\mathrm{Co} . \mathrm{KG}$ ) and zeolite Litosand (natural product Tasajeras, Empresa Geominera del Centro) under an artificial light regime and at $20^{\circ} \mathrm{C}$ for 45 days. The Agrobacterium tumefaciens LBA4404 and its derivatives carrying the TYLCV and TLV partial dimers were grown for $24 \mathrm{~h}$ in YEB-medium (per liter, $4 \mathrm{~g}$ of Lab-Lemco, $5 \mathrm{~g}$ of sucrose, $1 \mathrm{~g}$ of yeast extract, $5 \mathrm{~g}$ of bacteriological peptone, $0.5 \mathrm{~g}$ of $\mathrm{MgSO}_{4}, \mathrm{pH}$ 7.2) at $28^{\circ} \mathrm{C}$. Then the agrobacteria were diluted fivefold in medium containing (per liter) $0.4 \mathrm{~g}$ of yeast extract, $10 \mathrm{~g}$ of mannitol, $0.1 \mathrm{~g}$ of NaCL, $0.2 \mathrm{~g}$ of $\mathrm{MgSO}_{4}, 0.4 \mathrm{~g}$ of $\mathrm{K}_{2} \mathrm{HPO}_{4}, \mathrm{pH} 7$, and were grown to an optical density at $620 \mathrm{~nm}$ of 1 . For plant inoculation, the agrobacteria were resuspended in the Murashige and Skoog salts solution containing $0.4 \mathrm{mg}$ of acetosyringone per milliliter (Sigma-Aldrich), $\mathrm{pH}$ 5.5, and were infiltrated into the leaf (for tomato and $N$. benthamiana) or injected into the stem (for tomato plants), as previously described (Fuentes et al. 2009). For Southern blot analysis of virus replication, samples were taken from infiltrated tomato leaves at 7 days postinfiltration (dpi) and from top leaves of tomato and $N$. benthamiana plants at $27 \mathrm{dpi}$. Total DNA was extracted by the CTAB method (Doyle and Doyle 1990). Total DNA from each sample $(1 \mu \mathrm{g})$ was fractioned in a $0.8 \%$ agarose gel and was transferred to Hybond N+ (Amersham Pharmacia Biotech), according to the manufacturer's instruction, using a TE 80 vacuum blotting unit (Amersham Pharmacia Biotech). DNA was crosslinked to the membrane using an Ultraviolet Crosslinker device (Amersham Pharmacia Biotech). The hybridizations were performed at $65^{\circ} \mathrm{C}$, using the $\left[\alpha-{ }^{32} \mathrm{P}\right] \mathrm{dATP}-$ labeled TLV C1 (positions 2,168 to 1,687 ) DNA probe for detection of TLV replicative forms and a TYLCV CP gene (positions 315 to 1,091) DNA probe for detection of TYLCV and TLV replicative forms. Both probes were prepared by the random primer procedure according to the Primer-Gene Labeling system (Promega). Probe stripping was performed by washing the membrane at $80^{\circ} \mathrm{C}$ three times for $1 \mathrm{~h}$, using a solution of $0.1 \times \mathrm{SSC}(1 \times \mathrm{SSC}$ is $0.15 \mathrm{M} \mathrm{NaCl}$ plus $0.015 \mathrm{M}$ sodium citrate) containing $0.5 \%$ sodium dodecyl sulfate.

\section{Northern blot analysis and deep sequencing of sRNAs.}

Total RNA was extracted from tomato plants as described by Fuentes et al. (2006). The sRNA blot hybridization analysis was performed as described by Akbergenov et al. (2006) and Blevins et al. (2006), using DNA oligonucleotide probes complementary to TYLCV-, TLV-, transgene-, and tomato genome-derived sRNAs.

For sRNA sequencing, cDNA libraries were prepared from 19-30-nt RNA fractions following Illumina Small RNA TruSeq protocol at Fasteris AG as described previously (Aregger et al. 2012). The cDNA libraries were sequenced on the Illumina Genome Analyzer HiSeq2000 using a TruSeq SBS Kit v3. After trimming the adaptor sequences, the read datasets were mapped to the genome of Solanum lycopersicum (EnsemblPlants database), the consensus master genomes of TLV and TYLCV, and the complete sequences of binary vectors carrying the transgenes T1 and T2, using the Burrows-Wheeler Alignment Tool (BWA, version 0.5.9) (Li and Durbin 2009). Single-base resolution maps of TYLCV-, TLV- and transgene-derived siRNAs were created using BWA and a sRNA tool MISIS (Fasteris AG website) (Seguin et al. 2014b). Reads mapping to several positions on the reference sequence were randomly assigned to one of them. To account for a circular virus genome, the first 25 bases of the genome sequence were added to its $3^{\prime}$ end. For each reference genome and each sRNA size (20 to $25 \mathrm{nt}$ ), MISIS counted total number of reads and reads in forward and reverse orientation, thus generating single-base resolution maps on which, for each position starting from the $5^{\prime}$ end of the reference genome, the number of matches starting at this position in forward (first base of the read) and reverse (last base of the read) orientation for each read length was given. The reads mapped to the last 25 bases of the extended genome sequence were added to the reads mapped to the first 25 bases. MISIS generated two types of count tables, one with zero mismatches and another with up to two mismatches. Comparison of the two tables was informative for identifying and correcting potential mismatches between a reference sequence and the master genome sequence as well as for the initial identification of SNPs and short indels in viral quasispecies. De novo reconstruction of the consensus master genomes of TYLCV and TLV isolates from the field-inoculated plants was performed using the siRomics approach described by Seguin et al. (2014a).

\section{Transcriptome profiling of noninoculated tomato plants.}

Total RNA was extracted from tomato plants as described by Fuentes et al. (2006), using two plants each from the control 
nontransgenic line (wt-2, wt-4) and transgenic lines T1 (km-1, km-5) and T2 (B-1, B-5). Column-based cleanup followed by DNase digestion was performed on the isolated total RNA, using the RNeasy mini kit (Qiagen). RNA quality and quantity were analyzed using the Agilent 2100 Bioanalyzer (Agilent Technologies). Probe synthesis, microarray hybridization, and primary data analysis were performed at the Functional Genomics Center (University of Zurich). Briefly, $100 \mathrm{ng}$ of purified total RNA was used to synthesize Cy-3-labeled complementary RNA (cRNA), according to the manufacturer's instructions (Agilent Technologies). Fragmented cRNA $(1.6 \mu \mathrm{g})$ was used for hybridization on the commercial Solanum lycopersicum arrays (Agilent Technologies), according to the manufacturer's instructions. Microarray slides were then scanned with an Agilent Microarray $\mathrm{C}$ reader, using scan Control software version A.8.4.1. Raw data acquisition was performed using Feature Extraction software 10.7.3 (Agilent Technologies). The microarray data were deposited in the NCBI GEO database (accession number GSE63708).

The analysis of DE genes was performed mainly in two groups for comparison: T1 over control plants and T2 over control plants. Up- and down-regulated genes, with FDRadjusted $P$ values lower than 0.05 (FDR $<0.05$ ) were functionally annotated using Blast $2 \mathrm{GO}$ tools. The tomato sequences were taken from NCBI's GenBank. The annotation for each gene was obtained from Gene Ontology (Ashburner et al. 2000); enzymatic annotations were obtained from the Enzyme database (Bairoch 2000), the Interpro protein database (Hunter et al. 2012), and the KEGG database of biological pathways (Kanehisa et al. 2014). Additionally, the DE genes in both T1 and T2 lines with respect to the control plants with FDR $<0.05$ were further sorted based on fold changes, with the cut-off values for the upregulated genes as $\log 2$ ratio above 1 and for the downregulated genes as $\log 2$ ratio below -1 (Fig. 5C).

\section{ACKNOWLEDGMENTS}

We thank B. Patil for help with rolling circle amplification, R. Rajeswaran for help with blot hybridization, and A. Martin and L. Hernández for language editing. The work was supported by the Swiss National Science Foundation (31003A_143882 to M. M. Pooggin, and 31003A_122469 to T. Hohn and M. M. Pooggin).

\section{LITERATURE CITED}

Akbergenov, R., Si-Ammour, A., Blevins, T., Amin, I., Kutter, C., Vanderschuren, H., Zhang, P., Gruissem, W., Meins, F., Jr., Hohn, T., and Pooggin, M. M. 2006. Molecular characterization of geminivirusderived small RNAs in different plant species. Nucleic Acids Res. 34:462-471.

Aragão, F. J., and Faria, J. C. 2009. First transgenic geminivirus-resistant plant in the field. Nat. Biotechnol. 27:1086-1088, author reply 1088-1089.

Aragão, F. J., Nogueira, E. O., Tinoco, M. L., and Faria, J. C. 2013. Molecular characterization of the first commercial transgenic common bean immune to the Bean golden mosaic virus. J. Biotechnol. 166:42-50.

Aregger, M., Borah, B. K., Seguin, J., Rajeswaran, R., Gubaeva, E. G., Zvereva, A. S., Windels, D., Vazquez, F., Blevins, T., Farinelli, L., and Pooggin, M. M. 2012. Primary and secondary siRNAs in geminivirusinduced gene silencing. PLoS Pathog. 8:e1002941.

Ashburner, M., Ball, C. A., Blake, J. A., Botstein, D., Butler, H., Cherry, J. M., Davis, A. P., Dolinski, K., Dwight, S. S., Eppig, J. T., Harris, M. A., Hill, D. P., Issel-Tarver, L., Kasarskis, A., Lewis, S., Matese, J. C., Richardson, J. E., Ringwald, M., Rubin, G. M., and Sherlock, G.; The Gene Ontology Consortium. 2000. Gene ontology: Tool for the unification of biology. Nat. Genet. 25:25-29.

Bairoch, A. 2000. The ENZYME database in 2000. Nucleic Acids Res. 28:304-305.

Bananej, K., Kheyr-Pour, A., Salekdeh, G. H., and Ahoonmanesh, A. 2004 Complete nucleotide sequence of Iranian tomato yellow leaf curl virus isolate: Further evidence for natural recombination amongst begomoviruses. Arch. Virol. 149:1435-1443.

Blevins, T., Rajeswaran, R., Aregger, M., Borah, B. K., Schepetilnikov, M., Baerlocher, L., Farinelli, L., Meins, F., Jr., Hohn, T., and Pooggin, M. M.
2011. Massive production of small RNAs from a non-coding region of Cauliflower mosaic virus in plant defense and viral counter-defense. Nucleic Acids Res. 39:5003-5014.

Blevins, T., Rajeswaran, R., Shivaprasad, P. V., Beknazariants, D., SiAmmour, A., Park, H. S., Vazquez, F., Robertson, D., Meins, F., Jr. Hohn, T., and Pooggin, M. M. 2006. Four plant Dicers mediate viral small RNA biogenesis and DNA virus induced silencing. Nucleic Acids Res. 34:6233-6246.

Bonfim, K., Faria, J. C., Nogueira, E. O., Mendes, E. A., and Aragão, F. J. 2007. RNAi-mediated resistance to Bean golden mosaic virus in genetically engineered common bean (Phaseolus vulgaris). Mol. Plant-Microbe Interact 20:717-726.

Butterbach, P., Verlaan, M. G., Dullemans, A., Lohuis, D., Visser, R. G., Bai, Y., and Kormelink, R. 2014. Tomato yellow leaf curl virus resistance by $T y-1$ involves increased cytosine methylation of viral genomes and is compromised by cucumber mosaic virus infection. Proc. Natl. Acad. Sci. U.S.A. 111:12942-12947.

Csorba, T., Kontra, L., and Burgyán, J. 2015. viral silencing suppressors: Tools forged to fine-tune host-pathogen coexistence. Virology 479-480:85-103.

Desbiez, C., David, C., Mettouchi, A., Laufs, J., and Gronenborn, B. 1995. Rep protein of tomato yellow leaf curl geminivirus has an ATPase activity required for viral DNA replication. Proc. Natl. Acad. Sci. U.S.A. 92:5640-5644.

Dong, X., van Wezel, R., Stanley, J., and Hong, Y. 2003. Functional characterization of the nuclear localization signal for a suppressor of posttranscriptional gene silencing. J. Virol. 77:7026-7033.

Doyle, J. J., and Doyle, J. L. 1990. Isolation of plant DNA from fresh tissue. Focus 12:13-15.

Duffy, S., and Holmes, E. C. 2007. Multiple introductions of the Old World begomovirus Tomato yellow leaf curl virus into the New World. Appl. Environ. Microbiol. 73:7114-7117.

Dunoyer, P., Schott, G., Himber, C., Meyer, D., Takeda, A., Carrington, J. C., and Voinnet, O. 2010. Small RNA duplexes function as mobile silencing signals between plant cells. Science 328:912-916.

Friedmann, M., Lapidot, M., Cohen, S., and Pilowsky, M. 1998. A novel source of resistance to Tomato yellow leaf curl virus exhibiting a symptomless reaction to viral infection. J. Am. Soc. Hortic. Sci. 123 1004-1007.

Fuentes, A., Ramos, P. L., Fiallo, E., Callard, D., Sánchez, Y., Peral, R., Rodríguez, R., and Pujol, M. 2006. Intron-hairpin RNA derived from replication associated protein $\mathrm{C} 1$ gene confers immunity to tomato yellow leaf curl virus infection in transgenic tomato plants. Transgenic Res. 15:291-304

Fuentes, A. D., Ramos, P. L., Fernández, A. I., Tiel, K., Callard, D. 2009. Transgenic tobacco cells: A permissive system for the assessment of resistance strategies against Tomato yellow leaf curl virus. Biotecnologia Aplicada 26:127-132.

Fuentes, A. D., Ramos, P. L., Sánchez, Y., Callard, D., Ferreira, A., Tiel, K., Cobas, K., Rodríguez, R., Borroto, C., Doreste, V., and Pujol, M. 2008. A transformation procedure for recalcitrant tomato by addressing transgenic plant-recovery limiting factors. Biotechnol. J. 3:1088-1093.

Fusaro, A. F., Matthew, L., Smith, N. A., Curtin, S. J., Dedic-Hagan, J., Ellacott, G. A., Watson, J. M., Wang, M. B., Brosnan, C., Carroll, B. J., and Waterhouse, P. M. 2006. RNA interference-inducing hairpin RNAs in plants act through the viral defence pathway. EMBO (Eur. Mol. Biol. Organ.) Rep. 7:1168-1175.

Garcia-Ruiz, H., Takeda, A., Chapman, E. J., Sullivan, C. M., Fahlgren, N., Brempelis, K. J., and Carrington, J. C. 2010. Arabidopsis RNAdependent RNA polymerases and dicer-like proteins in antiviral defense and small interfering RNA biogenesis during Turnip mosaic virus infection. Plant Cell 22:481-496.

Gómez, O., Piñon, M., Martínez, Y., Quinones, M. 2004. Breeding for resistance to begomovirus in tropic-adapted tomato genotypes. Plant Breed. 123:275-279.

Hallan, V., and Gafni, Y. 2001. Tomato yellow leaf curl virus (TYLCV) capsid protein $(\mathrm{CP})$ subunit interactions: Implications for viral assembly. Arch. Virol. 146:1765-1773.

Hamilton, A. J., and Baulcombe, D. C. 1999. A species of small antisense RNA in posttranscriptional gene silencing in plants. Science 286:950952.

Hanley-Bowdoin, L., Bejarano, E. R., Robertson, D., and Mansoor, S. 2013. Geminiviruses: Masters at redirecting and reprogramming plant processes. Nat. Rev. Microbiol. 11:777-788.

Havecker, E. R., Wallbridge, L. M., Hardcastle, T. J., Bush, M. S., Kelly, K. A., Dunn, R. M., Schwach, F., Doonan, J. H., and Baulcombe, D. C. 2010. The Arabidopsis RNA-directed DNA methylation argonautes functionally diverge based on their expression and interaction with target loci. Plant Cell 22:321-334. 
Hunter, S., Jones, P., Mitchell, A., Apweiler, R., Attwood, T. K., Bateman, A., Bernard, T., Binns, D., Bork, P., Burge, S., de Castro, E., Coggill, P., Corbett, M., Das, U., Daugherty, L., Duquenne, L., Finn, R. D., Fraser, M., Gough, J., Haft, D., Hulo, N., Kahn, D., Kelly, E., Letunic, I., Lonsdale, D., Lopez, R., Madera, M., Maslen, J., McAnulla, C., McDowall, J., McMenamin, C., Mi, H., Mutowo-Muellenet, P., Mulder, N., Natale, D., Orengo, C., Pesseat, S., Punta, M., Quinn, A. F., Rivoire, C., SangradorVegas, A., Selengut, J. D., Sigrist, C. J., Scheremetjew, M., Tate, J., Thimmajanarthanan, M., Thomas, P. D., Wu, C. H., Yeats, C., and Yong, S. Y. 2012. InterPro in 2011: New developments in the family and domain prediction database. Nucleic Acids Res. 40:D306-D312.

Jupin, I., De Kouchkovsky, F., Jouanneau, F., and Gronenborn, B. 1994. Movement of tomato yellow leaf curl geminivirus (TYLCV): Involvement of the protein encoded by ORF C4. Virology 204:82-90.

Kanehisa, M., Goto, S., Sato, Y., Kawashima, M., Furumichi, M., and Tanabe, M. 2014. Data, information, knowledge and principle: Back to metabolism in KEGG. Nucleic Acids Res. 42:D199-D205.

Lapidot, M., and Friedmann, M. 2002. Breeding for resistance to whiteflytransmitted geminiviruses. Ann. Appl. Biol. 140:109-127.

Lapidot, M., Friedmann, M., Lachman, O., Yehezkel, A., Nahon, S. 1997. Comparison of reistance level to tomato yellow leaf curl virus among commercial cultivars and breeding lines. Plant Dis. 81:1425-1428.

Lefeuvre, P., Martin, D. P., Harkins, G., Lemey, P., Gray, A. J., Meredith, S., Lakay, F., Monjane, A., Lett, J. M., Varsani, A., and Heydarnejad, J. 2010. The spread of tomato yellow leaf curl virus from the Middle East to the world. PLoS Pathog. 6:e1001164.

Li, H., and Durbin, R. 2009. Fast and accurate long-read alignment with Burrows-Wheeler transform. Bioinformatics 25:589-595.

Lucioli, A., Sallustio, D. E., Barboni, D., Berardi, A., Papacchioli, V., Tavazza, R., and Tavazza, M. 2008. A cautionary note on pathogenderived sequences. Nat. Biotechnol. 26:617-619.

Luna, A. P., Morilla, G., Voinnet, O., and Bejarano, E. R. 2012. Functional analysis of gene-silencing suppressors from tomato yellow leaf curl disease viruses. Mol. Plant-Microbe Interact 25:1294-1306.

Mi, S., Cai, T., Hu, Y., Chen, Y., Hodges, E., Ni, F., Wu, L., Li, S., Zhou, H., Long, C., Chen, S., Hannon, G. J., and Qi, Y. 2008. Sorting of small RNAs into Arabidopsis argonaute complexes is directed by the 5' terminal nucleotide. Cell 133:116-127.

Miozzi, L., Pantaleo, V., Burgyán, J., Accotto, G. P., and Noris, E. 2013. Analysis of small RNAs derived from tomato yellow leaf curl Sardinia virus reveals a cross reaction between the major viral hotspot and the plant host genome. Virus Res. 178:287-296.

Molnar, A., Melnyk, C. W., Bassett, A., Hardcastle, T. J., Dunn, R., and Baulcombe, D. C. 2010. Small silencing RNAs in plants are mobile and direct epigenetic modification in recipient cells. Science 328: 872-875.

Montes, C., Castro, Á., Barba, P., Rubio, J., Sánchez, E., Carvajal, D., Aguirre, C., Tapia, E., DelÍ Orto, P., Decroocq, V., and Prieto, H. 2014. Differential RNAi responses of Nicotiana benthamiana individuals transformed with a hairpin-inducing construct during Plum pox virus challenge. Virus Genes 49:325-338.

Montgomery, T. A., Howell, M. D., Cuperus, J. T., Li, D., Hansen, J. E., Alexander, A. L., Chapman, E. J., Fahlgren, N., Allen, E., and Carrington, J. C. 2008. Specificity of ARGONAUTE7-miR390 interaction and dual functionality in TAS3 trans-acting siRNA formation. Cell 133:128-141.

Moriones, E., and Navas-Castillo, J. 2000. Tomato yellow leaf curl virus, an emerging virus complex causing epidemics worldwide. Virus Res. 71: 123-134.

Nagano, H., Fukudome, A., Hiraguri, A., Moriyama, H., and Fukuhara, T. 2014. Distinct substrate specificities of Arabidopsis DCL3 and DCL4. Nucleic Acids Res. 42:1845-1856.

Navas-Castillo, J., Sánchez-Campos, S., Noris, E., Louro, D., Accotto, G. P., and Moriones, E. 2000. Natural recombination between Tomato yellow leaf curl virus-Is and Tomato leaf curl virus. J. Gen. Virol. 81: 2797-2801.

Navot, N., Pichersky, E., Zeidan, M., Zamir, D., and Czosnek, H. 1991. Tomato yellow leaf curl virus: A whitefly-transmitted geminivirus with a single genomic component. Virology 185:151-161.

Noris, E., Jupin, I., Accotto, G. P., and Gronenborn, B. 1996. DNA-binding activity of the $\mathrm{C} 2$ protein of tomato yellow leaf curl geminivirus. Virology 217:607-612.
Pooggin, M., Shivaprasad, P. V., Veluthambi, K., and Hohn, T. 2003. RNAi targeting of DNA virus in plants. Nat. Biotechnol. 21:131-132.

Pooggin, M. M. 2013. How can plant DNA viruses evade siRNA-directed DNA methylation and silencing? Int. J. Mol. Sci. 14:15233-15259.

Ribeiro, S. G., Lohuis, H., Goldbach, R., and Prins, M. 2007. Tomato chlorotic mottle virus is a target of RNA silencing but the presence of specific short interfering RNAs does not guarantee resistance in transgenic plants. J. Virol. 81:1563-1573.

Rojas, M. R., Jiang, H., Salati, R., Xoconostle-Cázares, B., Sudarshana, M. R., Lucas, W. J., and Gilbertson, R. L. 2001. Functional analysis of proteins involved in movement of the monopartite begomovirus, Tomato yellow leaf curl virus. Virology 291:110-125.

Schuck, J., Gursinsky, T., Pantaleo, V., Burgyán, J., and Behrens, S. E. 2013. AGO/RISC-mediated antiviral RNA silencing in a plant in vitro system. Nucleic Acids Res. 41:5090-5103.

Seguin, J., Otten, P., Baerlocher, L., Farinelli, L., and Pooggin, M. M. 2014b. MISIS: A bioinformatics tool to view and analyze maps of small RNAs derived from viruses and genomic loci generating multiple small RNAs. J. Virol. Methods 195:120-122.

Seguin, J., Rajeswaran, R., Malpica-López, N., Martin, R. R., Kasschau, K. Dolja, V. V., Otten, P., Farinelli, L., and Pooggin, M. M. 2014a. De novo reconstruction of consensus master genomes of plant RNA and DNA viruses from siRNAs. PLoS One 9:e88513.

Settlage, S. B., See, R. G., and Hanley-Bowdoin, L. 2005. Geminivirus C3 protein: Replication enhancement and protein interactions. J. Virol. 79: 9885-9895.

Takeda, A., Iwasaki, S., Watanabe, T., Utsumi, M., and Watanabe, Y. 2008. The mechanism selecting the guide strand from small RNA duplexes is different among argonaute proteins. Plant Cell Physiol. 49:493-500.

Vanderschuren, H., Akbergenov, R., Pooggin, M. M., Hohn, T., Gruissem, W., and Zhang, P. 2007. Transgenic cassava resistance to African cassava mosaic virus is enhanced by viral DNA-A bidirectional promoterderived siRNAs. Plant Mol. Biol. 64:549-557.

Verlaan, M. G., Hutton, S. F., Ibrahem, R. M., Kormelink, R., Visser, R. G., Scott, J. W., Edwards, J. D., and Bai, Y. 2013. The tomato yellow leaf curl virus resistance genes $T y-1$ and $T y-3$ are allelic and code for DFDGD-class RNA-dependent RNA polymerases. PLoS Genet. 9:e1003399.

Wang, B., Li, F., Huang, C., Yang, X., Qian, Y., Xie, Y., and Zhou, X. 2014. $\mathrm{V} 2$ of tomato yellow leaf curl virus can suppress methylation-mediated transcriptional gene silencing in plants. J. Gen. Virol. 95:225-230.

Wang, X. B., Jovel, J., Udomporn, P., Wang, Y., Wu, Q., Li, W. X., Gasciolli, V., Vaucheret, H., and Ding, S. W. 2011. The 21-nucleotide, but not 22-nucleotide, viral secondary small interfering RNAs direct potent antiviral defense by two cooperative argonautes in Arabidopsis thaliana. Plant Cell 23:1625-1638.

Xie, Y., Zhao, L., Jiao, X., Jiang, T., Gong, H., Wang, B., Briddon, R. W., and Zhou, X. 2013. A recombinant begomovirus resulting from exchange of the C4 gene. J. Gen. Virol. 94:1896-1907.

Yang, X., Wang, Y., Guo, W., Xie, Y., Xie, Q., Fan, L., and Zhou, X. 2011. Characterization of small interfering RNAs derived from the geminivirus/betasatellite complex using deep sequencing. PLoS One 6: e16928.

Yoo, B. C., Kragler, F., Varkonyi-Gasic, E., Haywood, V., Archer-Evans, S., Lee, Y. M., Lough, T. J., and Lucas, W. J. 2004. A systemic small RNA signaling system in plants. Plant Cell 16:1979-2000.

Zrachya, A., Glick, E., Levy, Y., Arazi, T., Citovsky, V., and Gafni, Y. 2007 Suppressor of RNA silencing encoded by Tomato yellow leaf curl virusIsrael. Virology 358:159-165.

Zvereva, A. S., and Pooggin, M. M. 2012. Silencing and innate immunity in plant defense against viral and non-viral pathogens. Viruses 4:2578-2597.

\section{AUTHOR-RECOMMENDED INTERNET RESOURCES}

Blast2GO tools: https://www.blast2go.com

EnsemblePlants database, Solanum lycopersicum Heinz 1706: http://plants.ensembl.org/Solanum_lycopersicum/Info/Index Fasteris AG website: www.fasteris.com

Gene Expression Omnibus database, accession number GSE63708: http://www.ncbi.nlm.nih.gov/geo/query/acc.cgi?acc=GSE63708 